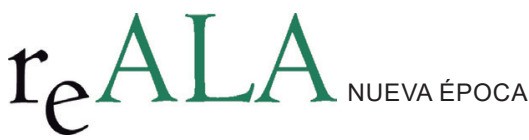

REALA, Nueva Época - N. ${ }^{\circ}$, enero-junio 2016 - ISSN: 1989-8975

DOI: http://dx.doi.org/10.24965/reala.voi5.10355

Agustín Juan Gil Franco

Ayuntamiento de Madrid

gilfa@madrid.es

\title{
Las competencias municipales de defensa de consumidores y usuarios desde la legislación autonómica y la Ley de racionalización y sostenibilidad de la Administración Local
}

\section{Resumen}

La defensa de consumidores y usuarios ha dejado de estar contemplada como competencia propia de los municipios tras la reforma de la Ley Reguladora de las Bases de Régimen Local operada por la Ley de racionalización y sostenibilidad de la Administración Local (LRSAL). Sin embargo, la raigambre de estas atribuciones en las administraciones municipales y la importante acción legislativa al respecto de las Comunidades Autónomas ha llevado a que sigan siendo consideradas como competencias propias de los municipios en la práctica totalidad del sistema legislativo autonómico. Éste, pues, se ha convertido en la principal fuente competencial de los municipios en esta materia. Además el trabajo parte de un análisis de las denominadas por la LRSAL como competencias distintas, cuál ha sido el origen de éstas y, a continuación, ha tratado de describir desde los ordenamientos autonómicos -y en menor medida de los locales-el desglose competencial de la materia de consumidores y usuarios.

Palabras clave

Municipios, consumidores y usuarios, competencias propias, competencias distintas, autonomía local, oficinas municipales de información al consumidor.

\section{The municipal competences on consumers and users defense from the local government legislation and the law of rationalization and sustainability of the local administration}

Abstract

The defense of consumers and users is no longer seen as self-competence of municipalities after the reform of the regulatory Law on Local Government by Law rationalization and sustainability of the local administration (LRSAL). However, the roots of these powers to local governments and major legislative action on the matter of the regions has led to continue being considered as competences of municipalities in almost all of the regional legislative system. This, therefore, has become the main source of municipal powers in this area. Work is based on an analysis of the socalled by the LRSAL different competences and which has been the source of these and then attempted to describe from autonomous systems-and to a lesser extent of local legal systems- the breakdown of powers matter of consumers and users.

Keywords

Municipalities, consumers and users, own skills, different skills, local autonomy, municipal consumer information offices. 


\section{SUMARIO}

1. Las competencias de consumidores y usuarios en los municipios tras la Ley de racionalización y sostenibilidad de la Administración Local.

1.1. Las competencias «distintas» entre la dialéctica competencias propias / competencias delegadas.

1.2. Carácter de las competencias locales de defensa de consumidores y usuarios.

2. Las competencias de los municipios sobre consumidores y usuarios en la legislación autonómica.

2.1. Información y educación del Consumidor.

2.2. La inspección de los bienes, productos y servicios.

2.3. El ejercicio de la potestad sancionadora.

2.4. El apoyo y fomento de las asociaciones de consumidores, y la promoción de órganos de participación ciudadana en materia de consumo.

2.5. La recepción de las reclamaciones de los consumidores de su ámbito territorial y la realización de mediación entre los consumidores y las empresas.

2.6. El fomento y la divulgación del Sistema Arbitral de Consumo.

2.7. El ejercicio de las acciones judiciales que en defensa de los consumidores y usuarios.

2.8. Adoptar las medidas urgentes y requerir las colaboraciones precisas en los supuestos de crisis o emergencias que afecten a la salud o seguridad de los consumidores y usuarios.

3. Conclusiones.

\section{LAS COMPETENCIAS DE CONSUMIDORES Y USUARIOS EN LOS MUNICIPIOS TRAS LA LEY DE RACIONALIZACIÓN Y SOSTENIBILIDAD DE LA ADMINISTRACIÓN LOCAL}

\subsection{Las competencias «distintas»: entre la dialéctica competencias propias / competencias delegadas}

La cuestión de las competencias en las Entidades locales básicas, auspiciada por la reciente reforma de 2013 de la Ley Reguladora de las Bases de Régimen Local (en adelante LRBRL), se centra en establecer un régimen competencial reducido a dos categorías fundamentales: las competencias propias -que se entienden directamente incardinadas en la autonomía local y que hacen comprensible a estas instituciones locales como tales- y las denominadas competencias delegadas tanto por el Estado, como por las CC.AA, en su caso'. Aunque la Ley pretende hacer de estos dos extremos el vértice competencial de las Entidades locales, con un régimen jurídico sustancialmente distinto, según veremos, no olvida que puede existir un ejercicio competencial distinto de los anteriores, de origen muy diverso, a pesar de sus intentos delimitadores, y que la ley califica como «competencias distintas»².

El artículo 7 de la LRBRL, central a la hora de definir el régimen jurídico de las competencias municipales, pretende simplificarlas, si bien a medida que avanza en su contenido, se complica y termina por admitir otras posibilidades, algunas, desde luego, presentes a la entrada en vigor de la reforma, y otras que puedan darse en un futuro legislativo. A nuestro modo de ver, el apartado 4 del artículo, viene a determinar cuatro casos concretos sobre la situación de este tipo de competencias a la entrada en vigor de la Ley:

a) Aquellas competencias autoatribuidas desde los supuestos del anterior art. 28 de la LRBRL33, cuyo único fundamento pudo ser amparado en los «desiderata» político-electorales, o bien en un deseo real de complementar la acción administrativa del Estado o de las Comunidades Autónomas sobre supuestos intereses locales.

1 Así lo determina de forma meridiana el art. 7.1 de la Ley /1985, de 2 de abril, reguladora de las Bases de Régimen Local, en la redacción dada por el número tres del artículo primero de la Ley 27/2013, 27 diciembre, de racionalización y sostenibilidad de la Administración Local (en adelante LRSAL), al señalar que "las competencias de las Entidades Locales son propias o atribuidas por delegación".

2 El art. 4 de la LRBRL, en su nueva redacción, establece que "las Entidades Locales solo podrán ejercer competencias distintas de las propias y de las atribuidas por delegación cuando no se ponga en riesgo la sostenibilidad financiera del conjunto de la Hacienda municipal, de acuerdo con los requerimientos de la legislación de estabilidad presupuestaria y sostenibilidad financiera y no se incurra en un supuesto de ejecución simultánea del mismo servicio público con otra Administración Pública. A estos efectos, serán necesarios y vinculantes los informes previos de la Administración competente por razón de materia, en el que se señale la inexistencia de duplicidades, y de la Administración que tenga atribuida la tutela financiera sobre la sostenibilidad financiera de las nuevas competencias. En todo caso, el ejercicio de estas competencias deberá realizarse en los términos previstos en la legislación del Estado y de las Comunidades Autónomas".

3 El ya derogado art. 28 LRBRL establecía que "los Municipios pueden realizar actividades complementarias de las propias de otras Administraciones públicas y, en particular, las relativas a la educación, la cultura, la promoción de la mujer, la vivienda, la sanidad y la protección del medio ambiente". Sin embargo la Disposición transitoria 2. ${ }^{a}$ no lo ha sido (Los Municipios ostentarán, además, en las materias a que se refiere el artículo 28 de esta Ley, cuantas competencias de ejecución no se encuentren conferidas por dicha legislación sectorial a otras Administraciones públicas).

REALA, Nueva Época, - N. ${ }^{\circ}$ 5, enero-junio 2016 - ISSN: 1989-8975 - DOI: 10.24965/reala.voi5.10355 
b) Aquellas señaladas en la Disposición transitoria $2 .^{\text {a }}$ en las que los Municipios ostentarían, además, en las materias a que se refiere el artículo 28 de la Ley, cuantas competencias de ejecución no se encuentren conferidas por dicha legislación sectorial a otras Administraciones públicas.

c) Aquellas que desde las propias Administraciones del Estado y Comunidades Autónomas le fueron atribuidas como complemento de las denominadas competencias propias municipales, basados en los principios descentralización y de máxima proximidad a la gestión administrativa a los ciudadanos, con una conexión mayor o menor con los «intereses locales» 4 .

d) Aquellas que, estando comprendidas como propias dentro del artículo 25 LRBRL, en su anterior redacción, tienen una atribución legislativa o normativa estatal o autonómica sectorial concreta. Es el caso por ejemplo de las atribuciones en defensa de consumidores y usuarios que se comprendían en el anterior art. 25.2 g) LRBRL5.

Y, sin perjuicio, de determinar un régimen jurídico específico «ad futurum» para que los municipios puedan recibir competencias calificadas como «distintas» a las «propias» y las «delegables», estas condiciones podrían tener también la condición de requisito «auditable» para las que ya se vinieran ejerciendo conforme a la clasificación que hemos expuesto. Los requisitos de sostenibilidad financiera y estabilidad presupuestaria y no simultaneidad del servicio público prestado y el principio de «una Administración, una competencia», son las condiciones que deben darse en el ejercicio de las «competencias distintas» por parte de los municipios, algo que es completamente concordante también con las competencias municipales propias ${ }^{6}$ por lo que el carácter «de facto» de las competencias ejercitables desde el régimen de las «competencias propias» y las «distintas» vendría a ser el mismo, salvo la garantía institucional precisada para las competencias propias 7 , sabiendo que el interés local es «un concepto jurídico de contenido legal» ${ }^{8}$.

La duda surge en la aplicación de estas condiciones legales para el ejercicio de las competencias municipales «distintas»: si estos requisitos son de aplicación para procesos de asunción competencial municipal futuros o si han de aplicarse a las ya asumidas. Es decir, la de atribuir carácter retroactivo a los requisitos establecidos por el art. 7.4 LRBRL para confirmar, de facto, la validez a las «competencias distintas» ya asumidas por los municipios. Para MORILLO-VELARDE no hay ningún factor revelador de una aplicación retroactiva de los nuevos mecanismos de atribución, máxime si tenemos en cuenta que en el anteproyecto de Ley existía una disposición transitoria que determinaba la evaluación de las «competencias distintas» que finalmente desapareció del proyecto de ley definitivamente enviado al Congreso ${ }^{9}$. Nosotros creemos que es plausible la revisión retroactiva de las "competencias distintas»-entonces impropias- que en su día fueran otorgadas a los municipios tanto por el Estado como por las CC.AA. dado que, y salvaguardado el núcleo del «interés local» garantizado «ex constitutione», las finalidades ex-

4 El Tribunal constitucional señala que "la autonomía que garantiza para cada entidad lo es en función del criterio del respectivo interés: interés del Municipio, de la Provincia, de la Comunidad Autónoma" STC, constitucional pleno, del 2 de febrero de 1981 (STC 4/1981), Ponente: Rafael GómEZ-FERRER MORANT. Sobre el interés local como único e indivisible: STS, contencioso sección 4, del 27 de octubre de 2010 (ROJ: STS 5821/2010). Núm. de Recurso: 100/2009.

5 Es interesante citar aquí lo prevenido por el art. 3.2 de la Ley 1/2014, de 25 de julio, de Adaptación del Régimen Local de la Comunidad de Madrid a la Ley $27 / 2013$, de 27 de diciembre, de Racionalización y Sostenibilidad de la Administración Local que señala que “las competencias atribuidas a los Municipios por leyes anteriores a la entrada en vigor de la Ley 27/2013, de 27 de diciembre, de Racionalización y Sostenibilidad de la Administración Local, se ejercerán por los mismos de conformidad con las previsiones contenidas en la norma de atribución, en régimen de autonomía y bajo su propia responsabilidad, de acuerdo con el artículo 7.2 de la Ley 7/1985, de 2 de abril, Reguladora de las Bases del Régimen Local, sin perjuicio de lo dispuesto en la presente Ley". En este mismo sentido la disposición adicional 1. ${ }^{a}$ de la Ley 5/2014, de 27 de mayo, de medidas urgentes derivadas de la entrada en vigor de la Ley 27/2013, de 27 de diciembre, de racionalización y sostenibilidad de la Administración local de Galicia.

6 Así lo especifica el art. 25.5 "La Ley determinará la competencia municipal propia de que se trate, garantizando que no se produce una atribución simultánea de la misma competencia a otra Administración Pública” y el apartado 4 del mismo artículo "La Ley a que se refiere el apartado anterior deberá ir acompañada de memoria económica que refleje el impacto sobre los recursos financieros de las Administraciones Públicas afectadas y el cumplimiento de los principios de estabilidad, sostenibilidad financiera y eficiencia del servicio o la actividad. La Ley debe prever la dotación de los recursos necesarios para asegurar la suficiencia financiera de las Entidades Locales sin que ello pueda conllevar, en ningún caso, un mayor gasto de las Administraciones Públicas".

7 Sobre el carácter plenamente tuitivo de la garantía institucional sobre la autonomía local, entre otras muchas podemos destacar la STS, contencioso sección 5, de 14 de diciembre de 2012. Núm. de Recurso: 3382/2009: "Ni que decir tiene que nada añade a este caso, como antes adelantamos, las referencias a la garantía institucional de la autonomía local, pues dicha garantía, como viene declarándose desde la STC 32/1981, y tras señalarse que la concreción de dichas competencias corresponde al legislador estatal y legisladores autonómicos, supone reconocer un núcleo indisponible para el legislador sin el cual las Administraciones Locales no sería reconocibles como tales". Núcleo dotado de una protección especial "la autonomía local consagrada en el art. 137 CE (con el complemento de los arts. 140 y 141 CE) se traduce en una garantía institucional de los elementos esenciales o del núcleo primario del autogobierno de los entes locales territoriales, núcleo que debe necesariamente ser respetado por el legislador (estatal o autonómico, general o sectorial) para que dichas Administraciones sean reconocibles en tanto que entes dotados de autogobierno" (SSTC 159/2001, de 5 de julio, FJ 4; 51/2004, de 13 de abril, FJ 9; la ya citada 252/2005, FJ 4, y 240/2006, de 20 de julio, FJ 8"). STC, constitucional pleno, del 19 de junio de 2012 (STC 132/2012) Recurso de inconstitucionalidad núm. 6433/2000.

8 STS, contencioso sección 5, del 22 de julio del 2011 (ROJ: STS 5299/2011). Núm. de Recurso: 4250/2007.

9 Morillo-Velarde PÉreZ, José Ignacio (2014) “Las competencias municipales en Andalucía (las medidas contenidas en el Decreto Ley 7/2014, de 20 de mayo)”. Revista Andaluza de Administración Pública núm. 89, págs. 28 y 29. 
presadas por el legislador son efectivamente la racionalidad y sostenibilidad financiera del sistema competencial local, en su expresión presente y futura ya que este mandato ya es una realidad desde la aprobación de la reforma constitucional de 27 de septiembre de $2011^{10}$.

Así parece deducirse, por ejemplo, del art. 3 de la Ley 1/2014, de 25 de julio, de Adaptación del Régimen Local de la Comunidad de Madrid a la Ley 27/2013, de 27 de diciembre, de Racionalización y Sostenibilidad de la Administración Local, cuando se afirma que «las competencias atribuidas a los Municipios por leyes anteriores a la entrada en vigor de la Ley 27/2013, de 27 de diciembre, de Racionalización y Sostenibilidad de la Administración Local, se ejercerán por los mismos de conformidad con las previsiones contenidas en la norma de atribución, en régimen de autonomía y bajo su propia responsabilidad, de acuerdo con el artículo 7.2 de la Ley 7/1985, de 2 de abril, Reguladora de las Bases del Régimen Local, sin perjuicio de lo dispuesto en la presente Ley. Las competencias indicadas en los apartados anteriores se desarrollarán bajo los principios de sostenibilidad, descentralización, proximidad, eficacia, eficiencia, autonomía y continuidad de los servicios». Y de forma más clara en la Comunidad Gallega, en la que se apuesta por esta misma continuidad, determinándose en el texto articulado de la ley de adaptación a la LRSAL ${ }^{11}$, qué se entienden por competencias municipales «distintas» anteriores a la LRSAL en un profuso art. $3 \cdot 3^{12}$, y por señalar de forma inequívoca que «las competencias atribuidas a las entidades locales por la legislación autonómica anterior a la entrada en vigor de la Ley 27/2013, de 27 de diciembre, de racionalización y sostenibilidad de la Administración local, continuarán ejerciéndolas ellas, rigiéndose por la indicada legislación o, en su caso, por el derecho estatal aplicable como supletorio, sin perjuicio de lo dispuesto en las disposiciones adicionales cuarta y quinta sobre la asunción por la Comunidad Autónoma de las competencias relativas a la educación, salud y servicios sociales ${ }^{13}$. Si bien, una interpretación de los anteriores preceptos legales ha sido la que, en efecto, determinó el control competencial y los parámetros financieros y de sostenibilidad de las mismas: "Ia continuidad en el ejercicio por las Entidades Locales de las competencias recogidas en el artículo 3.3 de la Ley 5/2014, de 27 de mayo, de medidas urgentes derivadas de la entrada en vigor de la Ley 27/2013, de 27 de diciembre de Racionalización y Sostenibilidad de la Administración Local, exigirá una evaluación previa de cada Entidad Local con respecto a la no existencia de duplicidades y de la sostenibilidad financiera. Ello sin perjuicio del control que, en ejecución de las competencias que corresponda ejercer a la Comunidad Autónoma, en tanto titular de la competencia material y de la tutela financiera de las entidades locales de su territorio, ejerza en orden a verificar el cumplimiento de los citados requisitos recogidos en el artículo 7.4 de la Ley de Bases de Régimen Local $^{14}$. De ahí que la Administración cedente y la Administración cesionaria deban reflexionar sobre el cumplimiento de los principios establecidos en el, ya repetido, art. 7.4 y el art. 2.1 LRBRL:

- $\quad$ sostenibilidad financiera del conjunto de la Hacienda municipal

- $\quad$ no ejecución simultánea del mismo servicio público

- afectación directamente al círculo de los intereses vecinales

- acción positiva para la descentralización, proximidad, eficacia y eficiencia en el ejercicio competencial.

10 La reforma afecta a una nueva redacción del art. 135 que se inicia con el punto 1.: " "Todas las Administraciones Públicas adecuarán sus actuaciones al principio de estabilidad presupuestaria...".

11 Ley 5/2014, de 27 de mayo, de la Comunidad Autónoma de Galicia, de medidas urgentes derivadas de la entrada en vigor de la Ley 27/2013, de 27 de diciembre, de racionalización y sostenibildiad de la Administración Local.

12 En concreto se relacionan: “a) La continuidad en la prestación de los servicios ya establecidos. b) La continuidad de la actividad de fomento ya establecida en ejercicios anteriores así como la realización de nuevas actuaciones de fomento que habían sido ya establecidas en los proyectos de establecimiento de servicios objeto de los informes de inexistencia de duplicidades y sostenibilidad financiera previstos en esta Ley. c) La modificación de la reglamentación de los servicios, de sus modalidades de prestación o de la situación, deberes y derechos de las personas usuarias con arreglo al artículo 297 de la Ley 5/1997, cuando no conllevara la realización de nuevas actividades prestacionales por los servicios ya establecidos o, aunque las conllevara, no supusieran una modificación sustancial de las condiciones de prestación del servicio, de la realización de la actividad o de su financiación, de acuerdo con lo establecido en esta Ley, o bien su ejercicio no supusiera la asunción de nuevas obligaciones financieras para la entidad local de acuerdo con la memoria económica justificativa que deberá incluirse en el expediente. d) La concurrencia a convocatorias de subvenciones o ayudas, así como la formalización de convenios de colaboración de concesión de subvenciones, para que las entidades locales realicen con carácter coyuntural actividades de información, de asesoramiento, de orientación, de mejora de la empleabilidad y formativas, y otras actividades que no supongan la creación de nuevos servicios municipales de acuerdo con el artículo 297 de la Ley 5/1997. Tampoco se entenderá como ejercicio de nuevas competencias la realización de las actividades citadas una vez obtenida la subvención. e) Las obras, servicios, ayudas, adquisiciones o suministros de emergencia, a causa de acontecimientos catastróficos, situaciones que supongan grave peligro o necesidades que afecten directamente a la seguridad pública. f) La colaboración entre administraciones entendida como el trabajo en común para la solución de aquellos problemas, también comunes, que pudieran formularse más allá del concreto reparto competencial en los distintos sectores de la acción pública, de acuerdo con el artículo 193.2 de la Ley 5/1997. g) El auxilio administrativo, de acuerdo con lo dispuesto en el artículo 193.4 de la Ley 5/1997.h) Los premios que se otorguen sin solicitud previa del beneficiario".

13 Es la Disposición adicional $1 .^{\text {a }}$ de la mencionada Ley gallega.

14 Es el punto 1. ${ }^{a}$ b), de la Resolución de 24 de marzo de 2015, de la Secretaría General de Coordinación Autonómica y Local, por la que se publica el Acuerdo de la Comisión Bilateral de Cooperación Administración General del Estado-Comunidad Autónoma de Galicia en relación con la Ley 5/2014, de 27 de mayo, de medidas urgentes derivadas de la entrada en vigor de la Ley 27/2013, de 27 de diciembre, d racionalización y sostenibilidad de Administración Local (BOE, 8 de abril de 2015).

REALA, Nueva Época, - N. ${ }^{\circ}$ 5, enero-junio 2016 - ISSN: 1989-8975 - DOI: 10.24965/reala.voi5.10355 
Todo ello bajo los también principios de colaboración, coordinación y respeto a los ámbitos competenciales respectivos ${ }^{15}$.

La cuestión a determinar es en qué medida dos principios constitucionales como son la autonomía local art. 137 CE- y el principio de estabilidad presupuestaria -art. 135 CE-, pueden predominar uno frente a otro y cómo la capacidad del legislador para delimitar la autonomía municipal pueda terminar «ahogándola», por mor de una interpretación rígida de dichos principios económicos de sostenibilidad del sector público. Es decir, cómo puede destacarse el verdadero contenido político en el ejercicio competencial de una entidad territorial, sin que el equilibrio básico de la Hacienda municipal se vea resentido, teniendo en cuenta que, como afirma la jurisprudencia, «el interés municipal es único e indivisible y acoger la tesis de la proporcionalidad sería contrario a la unidad de la persona jurídico-pública del Ayuntamiento, al modo de adoptarse sus acuerdos, a la ley 31/85 y al art. 103 CE que impone la objetividad de la Administración ${ }^{16}$ ». He aquí el verdadero reto de la nueva reforma de la LRBRL Ilamada a pivotar, sobre todo, en la colaboración, información y coordinación entre Administraciones. Sin embargo, algún autor ha señalado precisamente que la cercanía o proximidad al ciudadano se ve desvirtuada por la aparición de nuevos principios rectores que se plasman definitivamente en la reforma del artículo 2 de la LRBRL: la estabilidad presupuestaria y la sostenibilidad financiera ${ }^{17}$. De todas formas, la descentralización competencial que pueda darse en los municipios a través de este género -competencias distintas- exige, para ser real, de la suficiencia financiera ya que sólo se pueden ejercer políticas públicas propias sobre sectores administrativos habilitados por la ley si existe capacidad económica suficiente.

Un posible tercero género de competencias municipales puede venir señalado por aquellas que representaran la gestión ordinaria de servicios propios de la Administración autonómica, de conformidad con los Estatutos de Autonomía y la legislación de las Comunidades Autónomas ${ }^{18}$.

\subsection{Carácter de las competencias locales de defensa de consumidores y usuarios}

La defensa de consumidores y usuarios se incluía como competencia propia en la redacción original del art. 25.2 de la LRBRL de ahí que la legislación sectorial tanto estatal como autonómica haya atribuido explícitamente espacios competenciales a los municipios. Algo que lejos de ser una innovación legislativa no hacía sino reconocer la realidad administrativa relativa a esta materia. De esta manera, el art. 41 de la ya derogada Ley 26/1984, de 19 de julio, General para la Defensa de Consumidores y usuarios otorgaba a los municipios, entre otras competencias, la información y educación de los consumidores y usuarios, estableciendo las oficinas y servicios correspondientes, de acuerdo con las necesidades de cada localidad ${ }^{19}$. Es más, la propia STC 15/1989, de 26 de enero en la que se analizó la constitucionalidad de determinados preceptos de la mencionada Ley, entre otros el arriba mencionado art. 41, relativo a las competencias locales, señaló que en función de las competencias asumidas por los Estatutos de autonomía sobre esta materia, «a ellas corresponderá esa función delimitadora, en los términos mismos en que han sido asumidas ${ }^{20}$ ». Si bien es verdad, afirmaba el alto Tribunal, que esta materia es «de contornos imprecisos, que, con ser dificultoso en ocasiones la operación calificadora de una norma cuyo designio pudiera entenderse que es la protección del consumidor, la operación no resolvería el problema, pues la norma pudiera estar comprendida en más de una de las reglas definidoras de competencias ${ }^{21}$ ». Por tanto, las CC.AA se convierten en la fuente alternativa competencial, en materia de la defensa de consumidores y usuarios, frente al Estado, de tal manera que la fuente real de competencias municipales en la materia, se residencia de manera prioritaria en la legislación sectorial autonómica en detrimento de la legislación estatal de régimen local ${ }^{22}$. De esta manera, el Estatuto de autonomía

15 Art. 10.1 de la LRBRL.

16 STS, contencioso sección 4, del 27 de octubre de 2010 (ROJ: STS 5821/2010). Núm. de Recurso: 100/2009.

17 ORTIZ DE LA QUINTANA IBÁÑEZ (2014) “Las Competencias Municipales tras la modificación del régimen local operada con la aprobación de la Ley 27/2013. Especial referencia a la Comunidad Autónoma del País Vasco y Comunidad Foral de Navarra”. Academia Vasca de Derecho Boletín JADO. Bilbao, año XIII, núm. 26, enero-diciembre 2014, pág. 314.

18 Art. 8 de la LRBRL que permanece inalterado tras la reforma de la LRSAL.

19 Artículo que se completaba con "2. La inspección de los productos y servicios a que se refiere el artículo 2., 2, para comprobar su origen e identidad, el cumplimiento de la normativa vigente en materia de precios etiquetado, presentación y publicidad y los demás requisitos o signos externos que hacen referencia a sus condiciones de higiene, sanidad y seguridad. 3. La realización directa de la inspección técnica o técnico sanitaria y de los correspondientes controles y análisis, en la medida en que cuenten con medios para su realización, o promoviendo, colaborando o facilitando su realización por otras Entidades y Organismos. 4. Apoyar y fomentar las asociaciones de consumidores y usuarios. 5. Adoptar las medidas urgentes y requerir las colaboraciones precisas en los supuestos de crisis o emergencias que afecten a la salud o seguridad de los consumidores o usuarios. 6. Ejercer la potestad sancionadora con el alcance que se determine en sus normas reguladoras".

20 STC $15 / 1989$, de 26 de enero. FJ 11.

21 STC 71/1982, de 30 de noviembre. FJ $1 .^{\circ}$

22 Así se confirma en el Informe de la Dirección General de Coordinación de Competencias con las CC.AA y EE.LL del Ministerio de Hacienda y Administraciones Públicas de 13 de marzo de 2014, en el que, precisamente, se responde a numerosas consultas realizadas a consecuencia de la desaparición de la competencia de la “defensa de Consumidores y Usuarios” en la nueva redacción dada al art. 25.2 LRBRL por la LRSAL.

REALA, Nueva Época, - N. ${ }^{\circ}$ 5, enero-junio 2016 - ISSN: 1989-8975 - DOI: 10.24965/reala.voi5.10355 
sería norma primaria, -más en las reformas estatutarias de segunda generación-, en igualdad de condiciones con la norma básica estatal reguladora del régimen competencial local. Teniendo en cuenta que «el "derecho del consumidor", entendido como el "conjunto de reglas jurídicas que tienen por objeto proteger al consumidor" (STC 71/1982), difícilmente podrá encontrarse codificado en un conjunto normativo emanado de una sola de estas instancias, siendo más bien la resultante de la suma de las actuaciones normativas, enderezadas a este objetivo, de los distintos poderes públicos que integran el Estado, con base en su respectivo acervo competencial ${ }^{23}$ "), por ende ha de seguir contándose con las tras administraciones territoriales -Estado, CC.AA y municipios-, y sobre todo estas dos últimas, a la hora de configurar y aplicar el Estatuto del consumidor.

Esta circunstancia, del mayor protagonismo de las CC.AA en la materia, ha sido reflejada en el Texto Refundido de la Ley General para la Defensa de los Consumidores y Usuarios y otras leyes complementarias de 2007, que ha difuminado el dibujo competencial ${ }^{24}$ entre las tres Administraciones públicas territoriales no recogiendo listados concretos de materias diferenciadas para unas y otras. Tan sólo el artículo 81.1 del Texto Refundido alude a las Corporaciones locales con la misión de estudio y valoración del posible carácter abusivo de determinadas cláusulas y, en su caso, ejercitar las competencias que en materia de control y sanción, en relación con las condiciones generales de contratación elaboradas por empresas en sus relaciones comerciales con los consumidores ${ }^{25}$. De igual forma, la alusión a la conferencia Sectorial de Consumo, como máximo órgano de cooperación institucional del Estado y las CC.AA, a la que pueden acceder las Corporaciones locales a través de la asociación correspondiente con mayor implantación Estatal, manifiestan este carácter asimétrico de la Ley. A pesar de ello, la Ley explícitamente reconoce el papel competencial de los municipios en esta materia cuando señala el establecimiento, en su caso, de órganos permanentes de cooperación institucional, de conformidad con lo previsto en la regulación de las bases de régimen local ${ }^{26}$. Ninguna razón tendrían de existir dichas referencias, si no se tuvieran en cuenta las realidades competenciales con que contaban los municipios sobre la materia con anterioridad a la reforma descrita y las que siguen teniendo en la actualidad.

Esta puede ser una explicación para que de la nueva redacción del art. 25.2 LRBRL, se haya sustraído del núcleo competencial municipal, definido como propio y, por tanto, bajo el manto de la autonomía local y su protección, «la defensa de consumidores y usuarios». Aunque, lejos de no ofrecer duda alguna la intención del legislador local básico, los municipios seguirán conservando, en la nueva Ley como competencias propias, e incluso añadiendo una nueva (comercio ambulante ${ }^{27}$ ), las ferias, abastos, mercados, lonjas y comercio ambulante así como la protección de la salubridad pública. ¿De verdad realmente podemos separar la acción administrativa de la defensa de consumidores y usuarios, de las referidas a ferias abastos, mercados y comercio ambulante, en las que indudablemente hay consumidores y usuarios ${ }^{28}$ ? ¿Se refiere tan sólo a la concesión de licencias de actividades o declaraciones responsables, según el caso, sobre dichas materias?

Quizás sea menos explicable que la nueva redacción del art. 27.3 LRBRL, realizada por la antedicha Ley, ofrezca un elenco de competencias delegables en los municipios, tanto por el Estado como por las CC.AA y que, entre

23 STC 88/1986, de 1 de julio FJ $4 .^{\circ}$.

24 Como muestra un botón: el art. 17, artículo cuya rúbrica es "Información, formación y educación de los consumidores y usuarios", de referencia netamente municipal, se inicia como sigue: "los poderes públicos, en el ámbito de sus respectivas competencias..."

25 "Las empresas que celebren contratos con los consumidores y usuarios, a solicitud de la Agencia Española de Consumo y Seguridad Alimentaria y Nutrición, de los órganos o entidades correspondientes de las Comunidades Autónomas y de las Corporaciones locales competentes en materia de defensa de los consumidores y usuarios, dentro del ámbito de sus respectivas competencias, estarán obligadas a remitir las condiciones generales de contratación que integren dichos contratos, en el plazo máximo de un mes desde la recepción de la solicitud, al objeto de facilitar el estudio y valoración del posible carácter abusivo de determinadas cláusulas y, en su caso, ejercitar las competencias que en materia de control y sanción les atribuye esta ley".

26 Art. 40 del Real Decreto Legislativo, de 16 de noviembre de 2007, por el que se aprueba el Texto Refundido de la Ley General para la Defensa de los Consumidores y Usuarios y otras leyes complementarias.

27 De igual forma el comercio ambulante es otra actividad íntimamente unida al ejercicio de la defensa de consumidores y usuarios: "Eso es lo que ha hecho el Ayuntamiento, en ejercicio de sus competencias en materia sanitaria y de defensa de los consumidores en un supuesto en el que el único establecimiento que la Administración puede controlar es un vehículo que entra y sale repetidamente del término municipal, sin atender las indicaciones para que se someta a las condiciones establecidas para la venta en el término de Escalona fuera de establecimientos comerciales permanentes" STS, contencioso sección 4, del 9 de diciembre de 1995 (ROJ: STS 6247/1995). Núm. de Recurso (apelación): $3895 / 1991$.

28 En efecto la jurisprudencia señala este conjunto y la dificultad de su tratamiento separado: "Prescindiendo de cual sea el origen histórico de los mercados municipales de carácter fijo o periódico, cierto es que el artículo $25.2 \mathrm{~g}$ ) de la Ley 7/85 atribuye a los municipios la competencia en materia de mercados, abastecimientos, ferias y defensa de los consumidores y usuarios, así como que el artículo 127 del Reglamento de Servicios de las Corporaciones Locales (D. de 17 de junio de 1.955) ordena a dichas Corporaciones otorgar al concesionario la protección adecuada para que pueda prestar su servicio debidamente. Sin embargo, de dichos preceptos no es posible extraer la consecuencia de que un adecuado abastecimiento de la población haya de obtenerse impidiendo el acceso al mercado ocasional autorizado, precisamente, a productores o cultivadores que no desarrollen su tarea en el municipio de que se trate. Lo que primordialmente se trata de conseguir es el otorgar protección a los usuarios y consumidores, garantizando un abastecimiento adecuado y competitivo, sin que pueda entenderse como un acto de desprotección al concesionario de un puesto en el mercado regular el no limitar a los vecinos cultivadores el acceso al mercado ocasional" STS, contencioso sección 4 , del 5 de noviembre de 1997 (ROJ: STS 6577/1997). Núm. de Recurso: 12425/1991. 
otras, se haya incluido como delegable la «Inspección y sanción de establecimientos y actividades comerciales». Significa esto, que a pesar de la indudable conexión de las materias expuestas, los municipios ¿han perdido cualquier conexión con el régimen de los consumidores y usuarios? ¿Qué ocurrirá con las estructuras administrativas, los recursos humanos y los órganos de Arbitraje del Consumo que hayan sido creados por las corporaciones municipales y que hasta el momento han funcionado razonablemente bien? Pero, sobre todo, lo que la reforma de la LRBRL podría auspiciar es encontrarnos con una geometría asimétrica respecto de las competencias de defensa de consumidores y usuarios en los municipios, dado que la legislación básica sólo protege explícitamente como competencia delegable en los municipios la Inspección y sanción de establecimientos y actividades comerciales. De la misma forma, podría darse el camino inverso al realizado por la nueva Ley de racionalización y sostenibilidad de la Administración Local y otorgar el carácter de competencias propias de los municipios, las referidas a la defensa de consumidores y usuarios, incluidas las de inspección y sanción de establecimientos y actividades comerciales. Esta es una realidad que se reconoce explícitamente en el Estatuto de Autonomía de Andalucía ${ }^{29}$, aunque no ocurre lo mismo, por ejemplo, con el Estatuto de Autonomía de Cataluña que no las incluye, ni siquiera como delegables ${ }^{30}$. En cualquier caso, la regulación estatal o autonómica de la materia, sea en régimen de competencia propia o delegada, presenta caracteres diversos a los que habitualmente se entienden como ejercicio de competencias delgadas según la Ley 30/1992, de 26 de noviembre, sobre de Régimen Jurídico de las Administraciones Públicas y del Procedimiento Administrativo Común, que regula dicho régimen en su art. 13, ya que, por mor de la salvedad del art. 9, se establece un sistema especial en las relaciones interadministrativas entre la Administración General del Estado o la Administración de la Comunidad Autónoma con las Entidades que integran la Administración Local. Dicho sistema viene establecido, en primer término, por la legislación básica en materia de Régimen Local, y, en segundo término, por la aplicación supletoria de la propia ley 30/1992 ${ }^{31}$.

Pues bien, el régimen de delegación, según la redacción dada por la nueva Ley al apartado 4 del art. 27 LRBRL, puede determinar la dirección en el ejercicio de los servicios delegados, dictar instrucciones técnicas de carácter general y recabar, en cualquier momento, información sobre la gestión municipal, así como enviar comisionados y formular los requerimientos pertinentes para la subsanación de las deficiencias observadas. Ahora bien, la Administración delegante por muchas que sean las facultades de control, como señala la jurisprudencia constitucional, no puede situar al municipio en una posición de subordinación cuasijerárquica, sin capacidad alguna para determinar la organización de dichos servicios a la hora de ejecutar dichas potestades delegadas, dado que nos hallamos ante una atribución directamente insertada en el régimen de autonomía establecida en el art. $140 \mathrm{CE}^{32}$ y, por tanto, protegida por la garantía institucional. A este respecto -aunque en materia distinta-, creemos interesante resaltar un pronunciamiento del Tribunal Supremo sobre la cuestión del visado colegial y la posición de las Administraciones locales al respecto: «Las leyes autonómicas de desarrollo en materia colegial, así como las que puedan dictarse en el ejercicio de otras competencias sectoriales, quedan obligadas a respetar las bases normativas estatales que limitan los visados obligatorios. Y ello mismo se aplica, con mayor razón, a las Corporaciones Locales. Cosa distinta es que las Comunidades Autónomas (o, en su caso, las Corporaciones Locales) puedan regular otros medios de control propio, distintos del visado colegial obligatorio, o incluso, en ejercicio de su autonomía organizativa, pactar con los colegios profesionales los convenios correspondientes o contratar con ellos la prestación de 'los servicios de comprobación documental, técnica o sobre el cumplimiento de la normativa aplicable que consideren necesarios relativos a los trabajos profesionales'. Se tratará en todo caso, insistimos, de medios de control distintos del visado forzoso» ${ }^{33}$. Es decir que caben, cuando menos, en manos de los municipios facultades de concreción -posiblemente surgidas algunas sobre políticas propias de protección a consumidores y usuarios- desde las instrucciones generales realizadas por la Administración delegante.

Pero, siguiendo el hilo conductor de la ya derogada y subsumida Ley 26/1984, de 19 de julio, General para la Defensa de los Consumidores y Usuarios, podemos encontrar las bases sobre las que se agrupan las competencias

29 El art. 92.2 j) de la Ley Orgánica 2/2007, de 19 de marzo, de reforma del Estatuto de Autonomía para Andalucía: “Los Ayuntamientos tienen competencias propias sobre las siguientes materias, en los términos que determinen las leyes: j) Defensa de usuarios y consumidores".

30 Vid. art 84.2 de la Ley Orgánica 6/2006, de 19 de julio, de reforma del Estatuto de Autonomía de Cataluña.

31 La nueva Ley 40/2015, de 1 de octubre, de Régimen Jurídico del Sector Público, llamada a suceder a la Ley 30/1992, de 26 de noviembre, hace una referencia explícita a la delegación de competencias en las Administraciones locales en el art. 48.7, a propósito de los convenios interadministrativos: "Asimismo, cuando el convenio tenga por objeto la delegación de competencias en una Entidad Local, deberá cumplir con lo dispuesto en Ley 7/1985, de 2 de abril, Reguladora de las Bases del Régimen Local”. Su contenido es similar a la Ley $30 / 1992$ pero concreta un instrumento a través del cual llevar a cabo la delegación de competencias.

32 La Constitución garantiza la autonomía de los municipios. Estos gozarán de personalidad jurídica plena. Su gobierno y administración corresponde a sus respectivos Ayuntamientos, integrados por los Alcaldes y los Concejales. Los Concejales serán elegidos por los vecinos del municipio mediante sufragio universal, igual, libre, directo y secreto, en la forma establecida por la ley. Los Alcaldes serán elegidos por los Concejales o por los vecinos. La ley regulará las condiciones en las que proceda el régimen del concejo abierto.

33 STS, contencioso sección 3, del 14 de enero de 2013 (ROJ: STS 50/2013). Núm. de Recurso: 420/2010. 
locales en torno a la defensa de consumidores y usuarios. El dato no es ocioso porque ha sido la referencia en la labor legislativa de las distintas CC.AA, una vez que asumieron las competencias, vía estatuto, sobe la materia. En primer término, los municipios, según la precitada Ley, tienen competencias respecto de la información y educación de los consumidores y usuarios, en segundo lugar respecto de la inspección de los productos y servicios, incluyendo la realización directa de la inspección técnica o técnico-sanitaria; en tercer término, respecto del apoyo y fomento las asociaciones de consumidores y usuarios; en cuarto lugar, respecto de adopción de las medidas urgentes y el requerimiento de las colaboraciones precisas en supuestos de crisis o emergencias que afecten a la salud o seguridad de los consumidores o usuarios. Finalmente y como consecuencia de las anteriores, tiene atribuido el ejercicio de la potestad sancionadora ${ }^{34}$ con el alcance que se determine tanto por la Ley como en sus normas reguladoras 35 .

De igual forma, los municipios también tienen atribuidas competencias en relación con los sistemas extrajudiciales de resolución de conflictos entre los consumidores y usuarios y los empresarios y/o profesionales. En efecto, la normativa estatal prevé la creación de Juntas Arbitrales territoriales, constituidas mediante convenio de colaboración entre las Administraciones públicas y el Instituto Nacional del Consumo, en el que podrá preverse la constitución de delegaciones de la Junta Arbitral territorial, ya sean territoriales o sectoriales ${ }^{36}$. La redacción del precepto no deja lugar a dudas de que, dentro del concepto de Administraciones públicas, hemos de entender incluidas las Corporaciones locales municipales. Cuestión que se confirma, posteriormente, en su articulado, al establecer la necesaria presencia de las Entidades locales en el Consejo General del Sistema Arbitral de Consumo ${ }^{37}$, y, sobre todo, por la realidad ya que, en la actualidad, hay constituidas 40 Juntas Arbitrales de Consumo municipales y dos de Mancomunidades. En cualquier caso, ha de tenerse en cuenta que, en defecto de acuerdo de las partes, será competente la Junta Arbitral territorial en la que tenga su domicilio el consumidor, salvo que existieran varias Juntas Arbitrales territoriales competentes, en cuyo caso conocerá el asunto la de inferior ámbito territorial ${ }^{38}$.

\section{LAS COMPETENCIAS DE LOS MUNICIPIOS SOBRE CONSUMIDORES Y USUARIOS EN LA LEGISLACIÓN AUTONÓMICA}

Las 17 leyes autonómicas ${ }^{39}$, dedicadas a regular el régimen jurídico de los consumidores y usuarios, reservan espacio competencial a los municipios con mayor o menor relevancia en sus actuaciones. La mayor parte de ellas siguen el modelo clásico que se estatuyera con la primera ley estatal, la Ley 26/1984, de 19 de julio, General para

34 "de la doctrina que este Tribunal ha elaborado acerca de la potestad sancionadora de las Administraciones públicas a los que se hace referencia en las SSTC 124/2003, de 19 de junio, FJ 8, y 157/2004, de 21 de septiembre, FJ 15. En estas resoluciones se indica que la doctrina constitucional relativa a la potestad sancionadora toma como punto de partida su "carácter instrumental respecto del ejercicio de las competencias sustantivas, como hemos declarado en diversas resoluciones (SSTC 48/1988, de 22 de marzo, FJ 25; 227/1988, de 29 de noviembre, FJ 29; 96/1996, de 30 de mayo, FJ 7)" STC, constitucional pleno, del 19 de diciembre de 2013 (STC 218/2013). Cuestión de inconstitucionalidad núm. 8389/2010.

35 Sobre las facultades de las Ordenanzas para fijar los tipos sancionadores, es fundamental el Título XI de la LRBRL, adicionado por la Ley 57/2003, de 16 de diciembre, de medidas para la modernización del gobierno local. La medida legislativa viene a incorporar la doctrina del Tribuna Constitucional respecto de la necesaria y la jurisprudencia del Tribunal Supremo al respecto. Todo pasa por la evolución de la concepción de las Ordenanzas municipales desde una vinculación positiva a ley, a una vinculación negativa. Por ejemplo véase la STS, Contencioso sección 7, del 14 de Febrero del 2013 (ROJ: STS 693/2013). Recurso: 4118/2011, la STS, Contencioso sección 4 del 30 de Noviembre del 2010 (ROJ: STS 6428/2010). Recurso: $1200 / 2008$, etc.

36 Art. 5.2 b) del Real Decreto 231/2008, de 15 de febrero, por el que regula el Sistema Arbitral de Consumo.

37 En efecto, en el art. 13.4 h) del precitado Real Decreto 231/2008, de 15 de febrero, por el que regula el Sistema Arbitral de Consumo, se establece que "Son consejeros del Consejo General del Sistema Arbitral de Consumo: Dos representantes de la asociación de mayor implantación en el ámbito estatal representativa de las Entidades Locales".

38 Art. 8 del Real Decreto 231/2008, de 15 de febrero, por el que regula el Sistema Arbitral de Consumo.

39 Esta Leyes son: 1) Ley 11/1998, de 9 de julio, de Protección de los Consumidores de la Comunidad de Madrid (BOCM 16 de julio de 1998); 2) Ley $2 / 2012$, de 28 de marzo, gallega de protección general de las personas consumidoras y usuarias. (DOG núm. 69 , de 11 de Abril de 2012); 3) Ley del Principado de Asturias 11/2002, de 2 de diciembre, de los Consumidores y Usuarios (BOPA núm. 287, de 13 de Diciembre de 2002); 4) Ley de Cantabria 1/2006, de 7 de marzo, de Defensa de los Consumidores y Usuarios (BOC núm. 52 , de 15 de Marzo de 2006); 5) Ley 6/2003, de 22 de diciembre, de Estatuto de las Personas Consumidoras y Usuarias. (BOPV núm. 254, de 30 de Diciembre de 2003); 6) Ley Foral 7/2006, de 20 de junio, de Defensa de los Consumidores y Usuarios (BON núm. 78, de 30 de Junio de 2006); 7) Ley 2/2015, de 4 de marzo, por la que se aprueba el Estatuto del Consumidor de Castilla y León (BOCL núm. 49, de 12 de Marzo de 2015); 8) Ley 22/2010, de 20 de julio, del Código de consumo de Cataluña (DOGC núm. 5677, de 23 de Julio de 2010); 9) Ley 1/2011, de 22 de marzo, de la Generalitat, por la que se aprueba el Estatuto de los Consumidores y Usuarios de la Comunitat Valenciana (DOCV núm. 6487, de 24 de Marzo de 2011); 10) Ley 16/2006, de 28 de diciembre, de Protección y Defensa de los Consumidores y Usuarios de Aragón (BOA núm. 149, de 30 de Diciembre de 2006); 11) Ley 7/2014, de 23 de julio, de protección de las personas consumidoras y usuarias de las Illes Balears (BOIB núm. 103, de 31 de julio de 2014); 12) Ley 4/1996, de 14 de junio, del Estatuto de consumidores y usuarios de la Región de Murcia (BORM núm. 146, de 25 de Junio de 1996); 13) Ley 6/2001, de 24 de mayo, del Estatuto de los Consumidores de Extremadura (DOE núm. 72, de 23 de Junio de 2001); 14) Ley 11/2005, de 15de diciembre de 2005, del Estatuto del Consumidor de Castilla La Mancha (DOCM núm. 255, de 20 de Diciembre de 2005); 15) Ley 13/2003, de 17 de diciembre, de Defensa y Protección de los Consumidores y Usuarios de Andalucía (BOJA núm. 251, de 31 de Diciembre de 2003); 16) Ley 5/2013, de 12 de abril, para la defensa de los consumidores en la Comunidad Autónoma de La Rioja (BOLR núm. 49, de 19 de abril de 2013) y 17) Ley 3/2003, de 12 de febrero, del Estatuto de los Consumidores y Usuarios de la Comunidad Autónoma de Canarias (BOIC núm. 34, de 19 de Febrero de 2003). 
la Defensa de los Consumidores y Usuarios, si bien las Comunidades autónomas, de Cataluña, País Vasco, Castilla y León, Castilla La Mancha, Valencia, Canarias y Extremadura conciben la ley como un Estatuto, el Estatuto del Consumidor. Otra cuestión importante a destacar es que tan sólo dos Comunidades Autónomas han reformulado sus primeras leyes en la materia con posterioridad a la entrada en vigor de la Ley de racionalización y sostenibilidad de la Administración local: son, en concreto, la Comunidad de Castilla y León y la de Illes Balears. Entendemos significativa esta acotación, por cuanto que parecen haberse tenido en cuenta las previsiones del nuevo art. 25.2 de la LRBRL, en el que, como dijimos, desaparecían para los municipios las competencias de defensa de los consumidores y usuarios. En efecto, en ambas leyes desaparece toda alusión explícita a competencias municipales y es sustituida por expresiones -un tanto vagas- tales como «las Administraciones publicas de Castilla y León» o «las administraciones públicas competentes en materia de defensa de los consumidores... ». Tan sólo encontramos textos en los que la actividad de los municipios se reduce a «actuaciones» acotadas al ámbito de actividades de promoción e información de los derechos de consumidores y usuarios como Administración colaboradora en la ejecución, sin más consideraciones ${ }^{40}$, o las que se les pudiera delegar desde la propia Comunidad autónoma, en el caso de la Comunidad Autónoma de Illes Balears ${ }^{41}$.

Tres son los principios inspiradores en la distribución competencial CC.AA-municipios: 1) velar por el respeto a los legítimos intereses económicos y sociales de los consumidores en los términos establecidos en la legislación y normativa reguladora ${ }^{42}$, lo que dota a la actuación de las Administraciones concernidas de un carácter tuitivo básico para con el consumidor y usuario en sus relaciones comerciales; 2 ) respeto en el ejercicio competencial por parte de las distintas administraciones concernidas, implicando a las administraciones municipales, las cuales deben poner en conocimiento de los órganos regionales de defensa del consumidor cualesquiera datos o informaciones que pudieran ser relevantes para el ejercicio por aquéllos de sus competencias ${ }^{43}$; 3) colaboración y cooperación entre las administraciones locales y las CC.AA, y viceversa ${ }^{44}$, lo cual implica la celebración de acuerdos y convenios de colaboración en los aspectos que sean relevantes en la materia ${ }^{45}$, con fundamento en la distribución competencial propiciada por cada ley autonómica.

La legislación autonómica anterior a la LRSAL es clara al respecto y señala que corresponde a las corporaciones locales promover y desarrollar la protección y defensa de los consumidores y usuarios en sus respectivos ámbitos territoriales, con el alcance y contenido que les atribuya cada Ley y el resto de las normas jurídicas de aplicación ${ }^{46}$. Lo cual significa que los municipios, como también venimos recordando, son una pieza básica y relevante en este sector de la acción administrativa que necesita irremediablemente de la proximidad, eficacia y eficiencia de la que habla la LRBRL. Y la principal medida al respecto es el respeto a su autonomía, no tanto como una medida de protección como de fomento de políticas públicas de defensa de los consumidores y usuarios. Este es el sentido que aporta la Ley gallega de protección general de las personas consumidoras y usuarias al señalar explícitamente que las actuaciones autonómicas respetarán en todo caso, la autonomía local y se limitará a coordinar aquellas competencias concurrentes de las dos administraciones, y aquellas que así se determinen conjuntamente, atribuyéndose el control de dichas acciones al Parlamento de Galicia. Mandato que se extiende también para las provincias, mancomunidades, áreas metropolitanas y demás figuras de organización supramunicipal ${ }^{47}$. Sin embargo, otras Comunidades autónomas han optado por delimitar la actuación municipal tan sólo al ámbito de la inspección, es el caso de la Ley cántabra que desarrolla de manera explícita y detallada las competencias en materia de inspección y su correlativa potestad sancionadora en los municipios prescindiendo de otras competencias ${ }^{48}$. La Ley 22/2010, de 20 de julio, del Código de consumo de Cataluña, en cambio y sin señalar a las corporaciones locales,

40 Art. 94.2 y 3 de la Ley $7 / 2014$, de 23 de julio, de protección de las personas consumidoras y usuarias: "Los consejos insulares y los municipios proporcionarán a la Administración de la comunidad autónoma la información necesaria para el ejercicio de sus competencias. La Administración de la comunidad autónoma podrá establecer la colaboración de los municipios en campañas concretas de control de productos o servicios".

41 Es el caso del art. 93 de la Ley 7/2014, de 23 de julio, de protección de las personas consumidoras y usuarias: "La comunidad autónoma de las Illes Balears podrá delegar en los municipios competencias en materia de consumo, en los términos establecidos por la legislación de régimen local".

42 Art. 8 de la Ley 6/2001, de 24 de mayo, del Estatuto de los Consumidores de Extremadura.

43 Art. 46.3 de la Ley 4/1996, de 14 de junio, del Estatuto de consumidores y usuarios de la Región de Murcia. Lo cual viene a ser un trasunto de lo establecido en el art. 4.1 de la Ley 30/1992, de 26 de noviembre, del régimen jurídico de las Administraciones públicas y del procedimiento administrativo común (en adelante LRJPAC) y se inserta en el contenido del art. 10.1 de la LRBRL.

44 Sobre los convenios de colaboración vid. artículos 55 y 57 de la LRBRL, con sendas nuevas redacciones realizadas por la Ley 27/2013, 27 diciembre, de racionalización y sostenibilidad de la Administración Local.

45 Art. 97.2 de la Ley 13/2003, de 17 de diciembre, de Defensa y Protección de los Consumidores y Usuarios de Andalucía: “Tanto la Administración autonómica como las Diputaciones Provinciales cooperarán con los municipios para que puedan ejercer adecuadamente sus competencias en la materia."

46 Art. 52 de la Ley del Principado de Asturias 11/2002, de 2 de diciembre, de los Consumidores y Usuarios.

47 Art. 73.4 de la Ley 2/2012, de 28 de marzo, gallega de protección general de las personas consumidoras y usuarias.

48 Art. 33.3 de la Ley de Cantabria 1/2006, de 7 de marzo, de Defensa de los Consumidores y Usuarios.

REALA, Nueva Época, - N. ${ }^{\circ}$ 5, enero-junio 2016 - ISSN: 1989-8975 - DOI: 10.24965/reala.voi5.10355 
define los servicios públicos de consumo y establece un mínimo de funciones, de tal manera que cualquier órgano u organismo de titularidad pública dependiente de una administración pública catalana que lleve a cabo tareas de información, orientación y asesoramiento a las personas consumidoras, tiene la consideración de servicio público de consumo en el ámbito de su demarcación territorial y de acuerdo con sus competencias ${ }^{49}$. En el caso de la Comunidad Autónoma de Andalucía, la Ley de consumo exige de los Ayuntamientos, respecto de las competencias que puedan asumir por medio de la misma, su aceptación mediante acuerdo plenario y su comunicación formal a la Comunidad Autónoma ${ }^{50}$.

Es especialmente interesante que la Ley gallega atribuya a los municipios de modo específico la potestad de ordenanza para esta materia concreta de consumo ${ }^{51}$, como también la legislación Canaria, cuya Ley establece que «el ejercicio de las competencias tendrá que ser determinado por el correspondiente decreto u ordenanza ${ }^{52}$ », algo que no se ha recogido en la restante legislación autonómica.

Sea como fuere, los principales ítems competenciales de los municipios se agrupan en los epígrafes que se desarrollarán y que han partido de la realidad de las actuaciones públicas en esta materia por parte de los entes locales, las primeras administraciones, detrás de la Administración General del Estado, en el ejercicio de políticas públicas en la defensa de consumidores y usuarios.

\subsection{Información y educación del Consumidor}

La información y educación de los consumidores y usuarios es un deber competencial local con un trasfondo constitucional claro, ya que el art. 51.2 CE insta a las Administraciones en ese sentido. Partiendo de la idea de que los bienes o servicios puestos en el mercado deben ser seguros ${ }^{53}$, teniendo en cuenta que la seguridad es una realidad poliédrica, la acción local ha de partir de la realización de planes generales y de actuaciones singulares respecto de categorías y grupos de consumidores de riesgo y de atención especial. En dichos planes ha de asegurarse que dispongan de la información precisa y comprensible para el eficaz ejercicio de sus derechos y para que se les preste información sobre el adecuado uso y consumo de los bienes y servicios puestos a su disposición en el mercado ${ }^{54}$. El carácter tuitivo que hemos reseñado como hilo conductor de la acción de la administración municipal correspondiente, ha llevado incluso a intensificar su acción en sectores de población identificados como «grupos específicos de consumidores» que se encuentren en situaciones de inferioridad, desprotección o discapacidad por razón de su edad, origen o condición, en especial, los menores, las personas con capacidades disminuidas, personas mayores, inmigrantes y sectores económicos y sociales más vulnerables ${ }^{55}$. De igual manera, la acción normativa local ha contemplado a los consumidores afectados por situaciones coyunturales sobrevenidas, en situaciones catastróficas o de emergencia, o de perturbación grave en el abastecimiento o suministro de productos ${ }^{56}$.

Esta acción administrativa se debe encaminar, sobre todo, para asegurar la posición del consumidor ante el mercado y dirigir sus esfuerzos a fin de alcanzar el denominado "consumidor medio", normalmente informado y razonablemente atento y perspicaz, o, como la Jurisprudencia del Tribunal de Justicia de la Unión Europea ha acuñado: «el consumidor que esté razonablemente bien informado y sea razonablemente observador y prudente ${ }^{57}$ ». Este carácter finalista que se ha de otorgar a la información del consumidor tiene como objetivo reforzar su situación dentro del mercado de bienes y servicios, en donde su posición habitual es, en muchos casos, de una debilidad extrema. Información administrativa fundamentada "en un doble sentido: por un lado, dirigida a concienciar y convencer a los ciudadanos de tales objetivos y, de otro, indicando cómo y dónde pueden prestar su colaboración los

49 Ambas cuestiones se contienen en el art. 126-10 del Código de consumo de Cataluña.

50 Art. 97.5 de la Ley 13/2003, de 17 de diciembre, de Defensa y Protección de los Consumidores y Usuarios de Andalucía.

51 El Art. 71. 3. de Ley 2/2012, de 28 de marzo, gallega de protección general de las personas consumidoras y usuarias, lo señala: “Las entidades locales, con respeto a la normativa estatal y autonómica de aplicación, podrán aprobar ordenanzas en materia de consumo para el mejor cumplimiento de la normativa de defensa del consumidor".

52 Art. 46.2 de la Ley 3/2003, de 12 de febrero, del Estatuto de los Consumidores y Usuarios de la Comunidad Autónoma de Canarias.

53 Art. 11.1 del Real Decreto Legislativo 1/2007, de 16 de noviembre, por el que se aprueba el texto refundido de la Ley General para la Defensa de los Consumidores y Usuarios y otras leyes complementarias. Además el artículo 2(b) iv de la Directiva 2001/95/CE del Parlamento Europeo y del Consejo de 3 de diciembre de 2001, relativa a la seguridad general de los productos: "la seguridad de los productos debe evaluarse teniendo en cuenta todos los aspectos pertinentes, en particular las categorías de consumidores que pueden ser especialmente vulnerables a los riesgos que presentan los productos en cuestión, en particular los niños y las personas mayores".

54 Art. 27.1 del Real Decreto Legislativo 1/2007, de 16 de noviembre, por el que se aprueba el texto refundido de la Ley General para la Defensa de los Consumidores y Usuarios y otras leyes complementarias.

55 En este mismo sentido véase la Resolución del Parlamento Europeo de 22 de mayo de 2012 sobre una estrategia de refuerzo de los derechos de los consumidores vulnerables.

56 Art. 5 de la Ordenanza de Consumo de la Ciudad de Madrid (BO. Comunidad de Madrid núm. 89, de 15-04-2011).

57 González Vaqué, Luis, “La noción de consumidor medio según la jurisprudencia del Tribunal de Justicia de las Comunidades Europeas”, Revista de Derecho Comunitario Europeo, año 8, núm. 17, enero-abril 2004, pág. 57. 
ciudadano ${ }^{58}$ 》. De ahí que la información administrativa vaya más allá, por ejemplo, de las obligaciones impuestas por el Texto refundido respecto del etiquetado y presentación de los bienes y servicios cuyo contenido y forma debe ser de tal naturaleza que no induzca a error al consumidor y usuario ${ }^{59}$. La Ley de consumidores de Aragón añade que toda la información legalmente exigible figurará, al menos, en lengua castellana ${ }^{60}$ y la legislación gallega, que la formación y educación de los consumidores cuidará de la integración de la perspectiva de género ${ }^{61}$.

Instrumentos fundamentales para esta finalidad son el establecimiento de oficinas de información al consumidor cuya existencia es ya una tradición en las administraciones municipales. Las primeras se sitúan en la década de los ochenta del siglo pasado y fueron la respuesta de las Administraciones públicas a la crisis alimentaria del aceite de colza ${ }^{62}$. El paso de los años no ha hecho sino confirmar su existencia y su relevantisimo papel en la información de los consumidores y usuarios. Algunas leyes autonómicas las han definido como «establecimientos abiertos al público, creados por las entidades locales, que prestan el servicio de asesoramiento e información al consumidor y usuario y sirven de cauce para sus reclamaciones ${ }^{63}$, , incluyendo el legislador un mandato a las administraciones autonómicas respectivas en el sentido de su impulso, implantación y consolidación con una atribución competencial concreta a dichas oficinas ${ }^{64}$. E, incluso, el mandato de creación, bajo los criterios de eficacia y de mayor proximidad a los consumidores, de dichas oficinas en núcleos urbanos con una población superior a 5.000 habitantes de derecho o en aquellos municipios que, sin alcanzar tal cifra, tengan un alto grado de población flotante ${ }^{65}$. Mandato que incluso lleva a que en municipios con población inferior a la indicada, se potencie la creación de oficinas de información al consumidor a través de mancomunidades de municipios tal y como postulan las leyes de consumidores y usuarios de Andalucía, Cataluña, Extremadura y Valencia ${ }^{66}$. Por su parte, la Ley aragonesa también otorga competencias, con el carácter de propias, a las comarcas en materia de formación en programas de educación del consumo por sí o en colaboración con otras Administraciones Públicas y las asociaciones de consumidores y usuarios ${ }^{67}$, como también las Diputaciones en la Comunidad Autónoma de Andalucía ${ }^{68}$. Incluso, la Ley de Consumidores del País Vasco, señala la medida administrativa precisa para este impulso «fomentará, mediante convenios genéricos o singularizados, la creación de servicios municipales de consumo que integren los servicios de información, formación, control de mercado, inspección, sanción, justicias alternativas y todos los posibles servicios que se presten en el área del consumo ${ }^{69}$ ». Este marco legislativo competencial propicia, en unos casos, y, en otros, recoge la realidad de que las 52 capitales de provincia poseen oficinas municipales de información al consumidor, a las que se añaden las de otros municipios con volúmenes de población muy diferente: así por ejemplo, en la Comunidad de Madrid existen un total de 67 oficinas municipales de información al Consumidor, de las cuales 12 corresponden a distintas mancomunidades ${ }^{70}$.

En lo referente a la educación de los consumidores y usuarios las leyes autonómicas también han concedido competencias a los municipios, aunque no todas lo hacen de forma explícita y, menos, las que se refieren a la actividad educativa en un sentido autónomo y como acción administrativa específica. Las Comunidades Autónomas de

58 GUILlÉn CARAmÉs, Javier (2002), "El Estatuto jurídico del consumidor (política comunitaria, bases constitucionales y actividad de la Administración)”. Ed. Civitas. 1. ${ }^{a}$ Edición. Madrid. Pág. 355.

59 Art. 18 del Real Decreto Legislativo 1/2007, de 16 de noviembre, por el que se aprueba el texto refundido de la Ley General para la Defensa de los Consumidores y Usuarios y otras leyes complementarias.

60 Art. 24.3 de la Ley 16/2006, de 28 de diciembre, de Protección y Defensa de los Consumidores y Usuarios de Aragón.

61 Art. 47 de la Ley 2/2012, de 28 de marzo, gallega de protección general de las personas consumidoras y usuarias.

62 Por poner un ejemplo: la Oficina Municipal de Información al Consumidor de Burgos, fue constituida mediante acuerdo Pleno del Ayuntamiento de Burgos de fecha 3 de mayo de 1984 .

63 Art. 14.1 de la Ley 1/2011, de 22 de marzo, de la Generalitat, por la que se aprueba el Estatuto de los Consumidores y Usuarios de la Comunitat Valenciana.

64 Art. 16 de la Ley 11/2005, de 15 de diciembre de 2005, del Estatuto del Consumidor de Castilla La Mancha y el art. 14 de la Ley $1 / 2011$, de 22 de marzo, de la Generalitat, por la que se aprueba el Estatuto de los Consumidores y Usuarios de la Comunitat Valenciana.

65 Art 13. 2 de la Ley 6/2001, de 24 de mayo, del Estatuto de los Consumidores de Extremadura.

66 Véanse los arts. 13.3 Ley 6/2001, de 24 de mayo, del Estatuto de los Consumidores de Extremadura, art. 16 de la Ley 11/2005, de 15de diciembre de 2005, del Estatuto del Consumidor de Castilla La Mancha y el art. 21 de la Ley 13/2003, de 17 de diciembre, de Defensa y Protección de los Consumidores y Usuarios de Andalucía. En este último caso, la Ley tan sólo señala el deber de existencia de OMICs municipales, en los municipios de más de 20.000 habitantes. Para el art. 126-10.4 de la Ley 22/2010, de 20 de julio, del Código de consumo de Cataluña, la "Generalidad debe potenciar el desarrollo de los servicios públicos de consumo de ámbito local siguiendo criterios de eficacia, eficiencia y mayor proximidad de las personas consumidoras y debe asesorarlos en lo que sea necesario para la mejora del ejercicio de sus funciones".

67 Arts. 9.14) y 30 f) del Decreto Legislativo 1/2006, de 27 de diciembre, del Gobierno de Aragón, por el que se aprueba el texto refundido de la Ley de Comarcalización de Aragón.

68 Art. 98.1 a) de la Ley 13/2003, de 17 de diciembre, de Defensa y Protección de los Consumidores y Usuarios de Andalucía.

69 Art. 71 de la Ley 6/2003, de 22 de diciembre, de Estatuto de las Personas Consumidoras y Usuarias del País Vasco. En idénticos términos se pronuncia la Ley madrileña de consumidores y usuarios.

70 En el caso de Castilla y León hay un total de 28 oficinas de las que 9 corresponden a capitales de provincia. En Cataluña hay un total de 61 oficinas municipales de las cuales 46 se sitúan en la provincia de Barcelona. Fuente: CINDOC de la Agencia Española de Consumo, Seguridad Alimentaria y Nutrición. 
Madrid $^{71}$, Canarias ${ }^{72}$, Andalucía ${ }^{73}$, Valencia ${ }^{74}$, Asturias ${ }^{75}$ y País Vasco ${ }^{76}$, atribuyen la formación -y educación en el caso de la Comunidad Gallega77 - de consumidores y usuarios a los municipios como una acción refleja de las actividades de información, si bien dicha conceptualización no oculta una atribución competencial específica, de tal manera que permita transmitir a los mismos conocer sus derechos y la forma de ejercerlos junto al acercamiento a programas específicos de consumo. En cambio, bajo la rúbrica general de las «Administraciones Públicas en el ámbito de sus respectivas competencias», las leyes de las Comunidades Autónomas de Castilla y León, Extremadura y Cantabria parecen incluir a las municipios -aunque sin decirlo explícitamente- dentro del fomento y desarrollo de campañas informativas de divulgación o de estudio y análisis de determinados bienes y servicios, habilitando los medios necesarios para acercar esta información a los consumidores y empresarios ${ }^{78}$. La Ley extremeña tilda de educación la formación permanente referida a consumidores y usuarios con el objeto de desarrollar un comportamiento en libertad y responsabilidad en el consumo de productos, bienes y en la utilización de servicios. Además, asume como acción específica autonómica la formación especializada de educadores en materia de consumo ${ }^{79}$. Las Comunidades de Castilla La Mancha y Navarra, por su parte, confían a las administraciones municipales la realización de tareas de educación y formación en materia de consumo, mediante campañas informativas o programas dirigidos a mejorar el nivel de educación específica y formación de los consumidores ${ }^{80}$, a lo que añaden las Leyes de la Región de Murcia y de la Comunidad Valenciana una invitación específica: «la utilización de los medios de comunicación pública de titularidad local. Con este objeto, podrán recabar la colaboración de las Asociaciones de consumidores y usuarios ${ }^{81}$ ». Fruto de esta acción legislativa numerosas corporaciones locales ha realizado talleres educativos en los que se imparten enseñanzas relacionadas con alimentación y nutrición, etiquetado, aditivos, publicidad, la compra, servicios públicos, juego y juguete, seguridad infantil, eco-consumo, el euro, cuidado del entorno, entre otros temas. Con un carácter más general, la Ley de Aragón insta a su Gobierno al establecimiento de las colaboraciones precisas con los organismos o entidades públicas con competencias en materia de consumo para el desarrollo de programas de formación en los distintos municipios y comarcas junto a la suscripción de los convenios oportunos con las instituciones competentes en el ámbito educativo para la formación de especialistas en consumo ${ }^{82}$.

Debemos recordar que, dentro del ámbito de la Unión Europea, la educación y formación de consumidores y usuarios es un objetivo legislado dentro del Reglamento (UE) núm. 254/2014 del Parlamento Europeo y del Consejo, de 26 de febrero de 2014, sobre el Programa plurianual de Consumidores para el período 2014-2020, con la pretensión de profundizar en el conocimiento de derechos e intereses de los consumidores y los comerciantes; y generar conocimientos y capacidad en aras de una participación más efectiva de los consumidores en el mercado $^{83}$. Por su parte el art. 17 del Real Decreto Legislativo 1/2007, de 16 de noviembre, por el que se aprueba el texto refundido de la Ley General para la Defensa de los Consumidores y Usuarios y otras leyes complementarias, insta a que los poderes públicos, en el ámbito de sus respectivas competencias, fomenten la formación y educación de los consumidores y usuarios, asegurando que estos dispongan de la información precisa para un ejercicio eficaz de sus derechos, velando para que se les preste la información comprensible sobre el adecuado uso y consumo de los bienes y servicios puestos a su disposición en el mercado ${ }^{84}$. Las acciones formativas y educativas de los con-

71 Art.63.1 d) de la Ley 11/1998, de 9 de julio, de Protección de los Consumidores de la Comunidad de Madrid.

72 Art. 46.1 a) de la Ley 3/2003, de 12 de febrero, del Estatuto de los Consumidores y Usuarios de la Comunidad Autónoma de Canarias.

73 Art. 97.1 a) Ley 13/2003, de 17 de diciembre, de Defensa y Protección de los Consumidores y Usuarios de Andalucía.

74 Art. 13.2 e) del Ley 1/2011, de 22 de marzo, de la Generalitat, por la que se aprueba el Estatuto de los Consumidores y Usuarios de la Comunitat Valenciana.

75 Art. 52 a) de la Ley del Principado de Asturias 11/2002, de 2 de diciembre, de los Consumidores y Usuarios.

76 art. 68.1 c) de Ley 6/2003, de 22 de diciembre, de Estatuto de las Personas Consumidoras y Usuarias del País Vasco.

77 Art. 71.2 e) de la Ley $2 / 2012$, de 28 de marzo, gallega de protección general de las personas consumidoras y usuarias.

78 Art. 16.2 de la Ley 2/2015, de 4 de marzo, por la que se aprueba el Estatuto del Consumidor de Castilla y León y el art. 27.2 d) de la Ley de Cantabria 1/2006, de 7 de marzo, de Defensa de los Consumidores y Usuarios.

79 Art. 15.1 y Art. 15.2 a) de la Ley 6/2001, de 24 de mayo, del Estatuto de los Consumidores de Extremadura.

80 Art. 6.2 a), en relación con el art 16.2 e) de la Ley 11/2005, de 15-12-2005, del Estatuto del Consumidor de Castilla la Mancha y el art. 17 g) de la Ley foral $7 / 2006$, de 20 de junio, de Defensa de los Consumidores y Usuarios.

81 Art. 45.2 a) de la Ley 4/1996, de 14 de junio, del Estatuto de consumidores y usuarios de la Región de Murcia y el art. 13.2 c) de la Ley 1/2011, de 22 de marzo, de la Generalitat, por la que se aprueba el Estatuto de los Consumidores y Usuarios de la Comunitat Valenciana.

82 Art. 47 de la Ley 16/2006, de 28 de diciembre, de Protección y Defensa de los Consumidores y Usuarios de Aragón.

83 Dicho objetivo se encuentra regulado en el art. 3 de dicho Reglamento de la UE. Además se contemplan acciones específicas para los derechos básicos de los consumidores, la seguridad de los productos y la educación financiera.

84 Este artículo sobre el que tiene su origen es el art. 18 dela ya derogada Ley 26/1984, de 19 de julio, General para la Defensa de los Consumidores y Usuarios, y que la STC 15/1989, de 26 de enero, declaró como meramente supletorio de la legislación autonómica al respecto a no ser una competencia. El anterior art. 18 determinaba que 1. La educación y formación de los consumidores y usuarios tendrá como objetivos: a) Promover la mayor libertad y racionalidad en el consumo de bienes y la utilización de servicios. b) Facilitar la comprensión y utilización de la información a que se refiere el capítulo IV. c) Difundir el conocimiento de los derechos y deberes del consumidor o usuario y las formas más adecuadas para ejercerlos. d) Fomentar la prevención de riesgos que puedan derivarse del consumo de productos o de la utilización de servicios. e) Adecuar las pautas de consumo a una utilización racional de los recursos naturales. f) Iniciar y potenciar la formación de los educadores en este campo. 2. Para la consecución de los objetivos previstos en el

REALA, Nueva Época, - N. ${ }^{\circ}$ 5, enero-junio 2016 - ISSN: 1989-8975 - DOI: 10.24965/reala.voi5.10355 
sumidores y usuarios de las Corporaciones locales vienen a incardinarse sobre todo en programas específicos, sin contenido curricular alguno ${ }^{85}$, y siempre desde el apoyo a la divulgación de la información a través de la elaboración y publicación de material didáctico de apoyo a la educación en centros educativos y la formación en materias diversas para los consumidores y así ayudar a desarrollar un comportamiento libre, racional y responsable en el consumo de bienes y en la utilización de servicios. Una línea muy interesante es el fomento de Códigos de buenas prácticas de consumo y autocontrol como instrumentos de autorregulación empresarial o las acciones específicas de formación de los agentes sociales y económicos dentro del sector económico del consumo (Asociaciones de consumidores y usuarios, asociaciones de vecinos, etc. $)^{86} \mathrm{o} \mathrm{la}$, siempre interesante, apuesta entre los consumidores de las acciones de promoción del comercio justo ${ }^{87}$ y el fomento del cooperativismo de consumo ${ }^{88}$. De modo singular, el Ayuntamiento de Valencia prevé una línea de actuación que desarrolle actividades de animación sociocultural para jóvenes, que despierten el interés en la cuestión del consumo ${ }^{89}$.

\subsection{La inspección de los bienes, productos y servicios}

Para el ejercicio de dichas funciones ha de partirse de la idea de que los bienes o servicios puestos en el mercado deben ser seguros ${ }^{90}$ para lo cual han de considerarse seguros los bienes o servicios que, en condiciones de uso normales o razonablemente previsibles, incluida su duración, no presenten riesgo alguno para la salud o seguridad de las personas, o únicamente los riesgos mínimos compatibles con el uso del bien o servicio y considerados admisibles dentro de un nivel elevado de protección de la salud y seguridad de las personas ${ }^{91}$. BERMEJO VERA afirma que el motivo principal de la dotación y ejercicio de estas funciones de inspección y control es, en cualquier plano, la seguridad ${ }^{92}$. En efecto, si hay una actividad en la que encontrar mayor significado y sentido para la actividad inspectora es esta que ahora analizamos. Máxime si tenemos en cuenta que muchas de las medidas de control previo, tras la celebérrima Directiva de servicios, ha dado paso a la comprobación posterior. Es más, se obliga a las Administraciones a una intensificación de los controles «ex post»93 y así se ha traducido en la legislación administrativa básica ${ }^{94}$.

Por lo general, el conjunto de las leyes autonómicas atribuyen a los municipios la potestad de inspección como competencia propia, incluso así lo hacen aquellas leyes menos explícitas en el reconocimiento competencial de los mismos ${ }^{95}$, si bien otras parecen haberse adelantado al cambio normativo del art. 25.2 de la LRBRL y establecen simplemente las facultades de ejecución de las medidas que hayan sido adoptadas por la Administración autonómica en el ejercicio de la potestad de inspección. Es el caso de la Comunidad Autónoma Gallega que, a pesar de todo, sí incluye como competencias propias de los municipios: «la inspección, verificación, corrección y sanción del incumplimiento de los requisitos establecidos en la normativa de protección de los consumidores en el ámbito de la venta ambulante o no sedentaria, ferias y mercados ${ }^{96} \%$. Debemos recordar al respecto, que la reforma del art. 25.2 operada por la LRSAL suprimió las competencias locales en la defensa de consumidores y usuarios pero

número anterior, el sistema educativo incorporará los contenidos en materia de consumo adecuados a la formación de los alumnos.

85 La ordenanza reguladora de los servicios de consumo del Ayuntamiento de Valencia (BOP núm. 154, de 1-VII-93), en su art. 18 j) señalaba como misión de la OMIC la de "Realizar actividades de colaboración con el sistema educativo".

86 Véanse los arts. 31 y 46 de la Ordenanza de Consumo de la Ciudad de Madrid (BO. Comunidad de Madrid núm. 89, de 15-04-2011.

87 Con fecha 30 de mayo de 2008 el Pleno del Ayuntamiento de Madrid, aprobó por unanimidad la adhesión de la ciudad de Madrid al programa europeo de Ciudades por el Comercio Justo. Además de Madrid hay 13 ciudades españolas dentro de este programa: Bilbao, Málaga, Mallorca, Torrelavega...

88 Art. 127.12 f) de la Ley 22/2010, de 20 de julio, del Código de consumo de Cataluña.

89 Art. 18 i) de la Ordenanza municipal reguladora de los servicios de consumo del Ayuntamiento de Valencia (BOP núm. 154, de 1-VII93).

90 Dentro del ámbito de la Unión Europea. Téngase en cuenta la Directiva 2001/95/CE del Parlamento Europeo y del Consejo, de 3 de diciembre de 2001, relativa a la seguridad general de los productos (DOUE núm. 11, de 15-1-2002)

91 Art. 11 del Real Decreto Legislativo 1/2007, de 16 de noviembre, por el que se aprueba el texto refundido de la Ley General para la Defensa de los Consumidores y Usuarios y otras leyes complementarias.

92 BERMEJO VERA, José (1998), “La Administración inspectora”, RAP núm. 147, septiembre-diciembre 1998 , pág. 41.

93 ReBollo PUIG, Manuel (2013), "La actividad inspectora”, Ponencia para el VIII Congreso de la Asociación Española de Profesores de Derecho Administrativo, Alicante, febrero de 2013.

94 A este respecto hade tenerse en cuenta el actual art. 39.2 bis de la Ley 30/1992, de 26 de noviembre de Régimen Jurídico de las Administraciones Públicas y del Procedimiento Administrativo Común, en la redacción dada por la Ley 25/2009, de 22 de diciembre, de modificación de diversas Leyes para su adaptación a la Ley sobre el libre acceso a las actividades de servicios y su ejercicio: “Las Administraciones Públicas velarán por el cumplimiento de los requisitos aplicables según la legislación correspondiente, para lo cual podrán comprobar, verificar, investigar e inspeccionar los hechos, actos, elementos, actividades, estimaciones y demás circunstancias que se produzcan". Facultades que se reproducen en el art. 69.3 de la Ley 39/2015, de 1 de octubre, del Procedimiento Administrativo Común de las Administraciones Públicas.

95 Es el caso del art. 33.3 de la Ley 1/2006, de 7 de marzo, de Defensa de los Consumidores y Usuarios de Cantabria: “Los municipios, en el ámbito de sus competencias, también podrán desarrollar estas funciones a través de sus propios servicios de inspección, organizándolos de la forma que estimen más adecuada".

96 Art. 71.1 a) y b) de la Ley 2/2012, de 28 de marzo, gallega de protección general de las personas consumidoras y usuarias.

REALA, Nueva Época, - N. ${ }^{\circ}$ 5, enero-junio 2016 - ISSN: 1989-8975 - DOI: 10.24965/reala.voi5.10355 
que conservó las mismas sobre comercio ambulante y añadió en una nueva redacción del art. 27.3 de la LRBRL, como delegables en los municipios, las competencias de «inspección y sanción de establecimientos y actividades comerciales».

El ámbito de actuación de las labores de la inspección debe recaer sobre productos y servicios de uso o consumo común, ordinario y generalizado, puestos a disposición del consumidor para comprobar su origen e identidad, el cumplimiento de la normativa vigente en materia de precios, etiquetado, presentación y publicidad además de los signos externos que hacen referencia a sus condiciones de higiene, sanidad y seguridad ${ }^{97}$. De igual modo, la comprobación puede abarcar a que los bienes y servicios se ajusten razonablemente a las expectativas que pueden motivar su adquisición, derivadas de las descripciones realizadas en su presentación, publicidad, precio y otras circunstancias ${ }^{98}$. Añadiendo el Estatuto del Consumidor de Cataluña que la labor de inspección tiene naturalmente las facultades de adopción de medidas cautelares ${ }^{99}$. Es lo que se ha denominado por algunas leyes autonómicas como el ejercicio de la «inspección integral ${ }^{100}$ » y que incluso Guillén Caramés, entiende que debe extenderse «sobre los productos, bienes y servicios destinados a los consumidores, así como sobre el personal, los establecimientos y utensilios o maquinaria de toda clase utilizados para su producción, comercialización o prestación, y afecta a cualesquiera actividades, fases y aspectos de la elaboración, tratamiento, conservación, transporte distribución, etiquetado publicidad, etc. ${ }^{101}$ ». La Ley Gallega además señala que de las actuaciones de inspección, las Administraciones locales han de dar cuenta al órgano de la Administración autonómica competente en materia de consumo ${ }^{102}$, a los sólo efectos, añade la Ley de Castilla a Mancha, de la necesaria coordinación ${ }^{103}$. Lo cual no deja de ser chocante si nos atenemos a los principios inspiradores de la ley gallega en relación con el respeto a la autonomía local.

La Ley Extremeña, incluso, atribuye a los municipios las facultades para el fomento de la realización de ensayos o pruebas comparativas entre productos, bienes y servicios concurrentes y difundir sus resultados ${ }^{104}$.

Las leyes autonómicas insisten, como elemental principio de coordinación, que tanto las administraciones autonómicas como locales ajusten su actuación a los principios de colaboración y cooperación ${ }^{105}$, conforme a las reglas generales de las relaciones interadministrativas ${ }^{106}$. A este respecto, se muestra especialmente útil la fórmula del convenio de colaboración entre administraciones para desplegar con toda su eficacia la potestad inspectora en los diversos ámbitos territoriales, y evitar con ello reduplicaciones innecesarias. Esta figura del convenio de colaboración se recoge explícitamente en la Ley de Consumidores del País Vasco ${ }^{107}$. En el caso del Código de Consumo de Cataluña se apunta al ejercicio de la potestad inspectora en los municipios, en el ámbito de sus respectivas competencias, por razón de la materia ${ }^{108}$, lo cual parece llevar directamente a una norma reglamentaria para el desarrollo de tal previsión.

De igual forma, algunas leyes propician la elaboración de Planes de actuación generales o también de planes sectoriales en los que se fijen los objetivos y se determinen las prioridades de la acción pública en esta materia ${ }^{109}$, con la participación de las Entidades locales y los Consejos de Consumo ${ }^{10}$. Finalmente, de be destacarse que todos los inspectores de consumo, en el ejercicio de sus funciones, tienen el carácter de agentes de la autoridad y, para el desarrollo de sus funciones, pueden recabar el apoyo de las Fuerzas y Cuerpos de Seguridad cuando encuentren resistencia u obstrucción al ejercicio de su actividad ${ }^{111}$. Para ello, señalan algunas leyes autonómicas, deberá ir debidamente acredi-

97 Art. 68.1 a) de la Ley 6/2003, de 22 de diciembre, de Estatuto de las Personas Consumidoras y Usuarias del País Vasco.

98 Art.34 de la Ley 11/1998, de 9 de julio, de Protección de los Consumidores de la Comunidad de Madrid.

99 Art. 321-2.2 de la Ley 22/2010, de 20 de julio, del Código de consumo de Cataluña.

100 Art. 24.1 de la Ley 11/2005, de 15 de diciembre, del Estatuto del Consumidor de Castilla La Mancha.

101 GUILLÉn CARAMÉS, Javier “op. cit.”, pág. 508.

102 Art. 71.4 de la Ley 2/2012, de 28 de marzo, gallega de protección general de las personas consumidoras y usuarias.

103 Art. 6.2 de la Ley 11/2005, de 15 de diciembre, del Estatuto del Consumidor de Castilla La Mancha.

104 Art. 12 c) de la Ley 6/2001, de 24 de mayo, del Estatuto de los Consumidores de Extremadura.

105 Es especialmente interesante el art. 22.3 de la Ley 4/1996, de 14 de junio, del Estatuto de consumidores y usuarios de la Región de Murcia en le que establece expresamente que "actuarán coordinadamente, colaborarán entre sí y se informarán recíprocamente de las irregularidades que detecten y cuya represión corresponda a otros órganos. Igualmente, prestarán la asistencia, especialmente de carácter técnico, que les requieran los órganos competentes en materia de defensa del consumidor y usuario".

106 Art. 65.3 de la Ley 11/1998, de 9 de julio, de Protección de los Consumidores de la Comunidad de Madrid. Sobre los convenios de colaboración interadministrativos véanse los arts. 47 a 52 de la Ley 40/2015, de 1 de octubre, de Régimen Jurídico del Sector Público. En la actualidad existe un convenio de colaboración entre la Comunidad de Madrid y el Ayuntamiento de Madrid, concluido el 3 de junio de 2013 , en el que precisamente se establece un programa específico de "Inspección y control de mercado", en el que se realiza una distribución de funciones "ratione materiae".

107 Art. 70.3 de la Ley 6/2003, de 22 de diciembre, de Estatuto de las Personas Consumidoras y Usuarias del País Vasco.

108 Art. 126-11.1 de la Ley 22/2010, de 20 de julio, del Código de consumo de Cataluña.

109 Art. 100.1 de la Ley 13/2003, de 17 de diciembre, de Defensa y Protección de los Consumidores y Usuarios de Andalucía.

110 Art. 70.2 de la Ley 6/2003, de 22 de diciembre, de Estatuto de las Personas Consumidoras y Usuarias del País Vasco.

111 Art. 66 de la Ley 16/2006, de 28 de diciembre, de Protección y Defensa de los Consumidores y Usuarios de Aragón, el art. 23.1 de la Ley 4/1996, de 14 de junio, del Estatuto de consumidores y usuarios de la Región de Murcia y el art. 45 de la Ley 6/2003, de 22 de diciembre, de Estatuto de las Personas Consumidoras y Usuarias del País Vasco, entre otras.

REALA, Nueva Época, - N. ${ }^{\circ}$ 5, enero-junio 2016 - ISSN: 1989-8975 - DOI: 10.24965/reala.voi5.10355 
tado y se comportará, en todo momento, con la debida corrección, prudencia y discreción. Su actividad será siempre respetuosa con los administrados, proporcionada y ponderada, perturbando sólo en lo estrictamente necesario la actividad profesional de los inspeccionados. Puede acceder y examinar los documentos mercantiles, contables o de cualquier otro tipo que resulten relevantes para la investigación, y podrá obtener copia o reproducción de los mis$\operatorname{mos}^{112}$. En todo caso, estará obligado a mantener estricto sigilo profesional respecto a las informaciones obtenidas ${ }^{113}$.

\subsection{El ejercicio de la potestad sancionadora}

Reflejo del ejercicio de la potestad de inspección, es la potestad sancionadora que ya poseen las corporaciones locales de suyo para el ejercicio de sus competencias, según la LRBRL ${ }^{114}$, si bien las leyes autonómicas de consumidores les atribuyen expresamente ${ }^{115}$ esta potestad para la materia de consumo ya que constituye un tema de trascendencia vital para la adecuada protección del consumidor y su seguridad. Esta «vis expansiva» de dicha potestad «resulta del todo comprensible ante el ingente número de incumplimientos de las normas reguladoras de la materia por los diversos agentes que operan en el mercado ${ }^{116} »$.

De igual forma, algunas leyes autonómicas incluyen un principio de territorialidad respecto de las infracciones cometidas: «las infracciones se entienden cometidas en cualquiera de los lugares en los que se desarrollen las acciones u omisiones que conforman la conducta típica o se materialice la lesión o riesgo para los intereses de los consumidores o usuarios. No obstante, si la conducta tipificada está directamente vinculada al establecimiento o superficie comercial en los que se desarrolla la actividad, la infracción se entenderá cometida en el término municipal donde radique el inmueble referido ${ }^{117}$ »; como también una modulación del ejercicio de la potestad sancionadora local respecto de determinados tipos, según su gravedad y la sanción prevista, o si, por ejemplo, el hecho tipificado diera lugar al inicio del correspondiente procedimiento sancionador, en primer término, por los órganos competentes de la Administración autonómica correspondiente ${ }^{118}$. Se impone también a las Entidades locales, en ciertas leyes autonómicas, a los efectos de la necesaria coordinación respecto a la consideración de antecedentes y para evitar una duplicidad de las sanciones, poner en conocimiento al órgano competente de la Comunidad autónoma, los procedimientos que inicien y de las sanciones que impongan ${ }^{119}$. La Ley de consumidores de la Rioja impone informar a las asociaciones de consumidores sobre sanciones firmes impuestas por infracciones contra los derechos de los consumidores $^{120}$.

Las competencias sancionadoras se amplían a las posibles mediadas cautelares a aplicar en situaciones de ámbito local y se puedan afrontar en su totalidad dentro del término municipal. En caso contrario, los municipios sólo podrán adoptar provisionalmente las que sean urgentes ${ }^{121}$. Caben dichas medidas cautelares cuando: a) existan indicios racionales de riesgo para la seguridad que ya se pusieran de manifiesto en el transcurso de las actuaciones de inspección o bien como consecuencia de los resultados de los análisis emitidos por laboratorios oficiales o privados acreditados; b) se pudieran ocasionar graves vulneraciones de los derechos o intereses económicos de los consumidores; c) se den situaciones de urgencia.

Cuestión importante a tener en cuenta es la posible colaboración de la Ordenanzas locales a la hora delimitar los tipos infractores. La Ley 57/2003, de 16 de diciembre, de medidas para la modernización del gobierno local, que añadiera el Titulo XI a la LRBRL, significó una respuesta legislativa a las consecuencias del principio de legalidad sancionadora aplicado al ámbito local, sobre la senda que marcara el Tribunal Constitucional en la STC 132/2001, de 8 de junio, que ya advirtiera que «la mera atribución por ley de competencias a los Municipios -conforme a la exi-

112 Art. 46.3 de la Ley 6/2003, de 22 de diciembre, de Estatuto de las Personas Consumidoras y Usuarias del País Vasco.

113 Art. 35.3 de la Ley 11/1998, de 9 de julio, de Protección de los Consumidores de la Comunidad de Madrid.

114 Art. 4 f) de la Ley $7 / 1985$, de 2 de abril, reguladora de las Bases del Régimen Local.

115 Véase el art. 73.2 y 74.3 de la Ley 16/2006, de 28 de diciembre, de Protección y Defensa de los Consumidores y Usuarios de Aragón, el art. 95 de la Ley 13/2003, de 17 de diciembre, de Defensa y Protección de los Consumidores y Usuarios de Andalucía, el art. 45 de la Ley de Cantabria 1/2006, de 7 de marzo, de Defensa de los Consumidores y Usuarios, el art. 63.1 e) de la Ley 11/1998, de 9 de julio, de Protección de los Consumidores de la Comunidad de Madrid, entre otras. El art. 35 de la Ley 11/2005, de 15 de diciembre, del Estatuto del Consumidor de Castilla La Mancha, específica que la potestad sancionadora se ejercerá por "los órganos de las Corporaciones locales en los términos establecidos en la presente Ley y en las Ordenanzas Municipales".

116 GUILLÉn CARAMÉs, Javier “op. cit.”, pág. 546.

117 Art. 47 de la Ley de Cantabria 1/2006, de 7 de marzo, de Defensa de los Consumidores y Usuarios, el art. 36 de la Ley 11/2005, de 15de diciembre, del Estatuto del Consumidor de Castilla La Mancha, y el art. 96 de la Ley 13/2003, de 17 de diciembre, de Defensa y Protección de los Consumidores y Usuarios de Andalucía, entre otras.

118 Art. 45.1 c) de la Ley de Cantabria 1/2006, de 7 de marzo, de Defensa de los Consumidores y Usuarios.

119 Art. 81.2 de la Ley 5/2013, de 12 de abril, para la defensa de los consumidores en la Comunidad Autónoma de La Rioja.

120 Art. 16 g) de la Ley 11/2005, de 15de diciembre, del Estatuto del Consumidor de Castilla La Mancha.

121 Art. 45 C) de la Ley 4/1996, de 14 de junio, del Estatuto de consumidores y usuarios de la Región de Murcia. En este mismo sentido el art. 97.1 d) de la Ley 13/2003, de 17 de diciembre, de Defensa y Protección de los Consumidores y Usuarios de Andalucía. 
gencia del art. 25.2 LBRL- no contiene en sí la autorización para que cada Municipio tipifique por completo y según su propio criterio las infracciones y sanciones administrativas en aquellas materias atribuidas a su competencia. No hay correspondencia, por tanto, entre la facultad de regulación de un ámbito material de interés local y el poder para establecer cuándo y cómo el incumplimiento de una obligación impuesta por Ordenanza Municipal puede o debe ser castigada». Por su parte, la jurisprudencia del Tribunal Supremo, anterior a dicha ley, ya señalaba que «las Ordenanzas locales tienen abierta la posibilidad de tipificar infracciones y sanciones, aunque no por supuesto de forma genérica e indiscriminada ${ }^{122}$ ». Pero si ya con esta modificación legislativa se habilitaba a las Ordenanzas para la tipificación de infracciones y sanciones ante la posible carencia legislativa sectorial, es evidente que cabría dicha acción normativa a la hora de delimitar determinados tipos infractores ${ }^{123}$, teniendo en cuenta el principio de vinculación negativa a la Ley por parte de la Ordenanza ${ }^{124}$.

\subsection{El apoyo y fomento de las asociaciones de consumidores, y la promoción de órganos de participación ciuda- dana en materia de consumo}

El artículo 51.2 de la CE instaba a los poderes públicos el fomento de organizaciones de consumidores y usuarios y su participación en las cuestiones que puedan afectarles, en los términos que la ley estableciera. Mandato que las diversas leyes de consumo autonómicas han asumido y que han trasladado al mismo tiempo, en su mayoría, a las Administraciones municipales dentro de su ámbito territorial. Sin embargo, no se contemplan competencias de apoyo y fomento de las asociaciones de consumidores y usuarios, las Comunidades Autónomas de Cataluña, Valencia, Illes Balears, Castilla y León y Canarias.

Esta actividad de fomento, desde luego, aparece muy delimitada a su propio ámbito en cuanto a los planes que realicen en su territorio y en beneficio de sus vecinos ${ }^{125}$. El correlato a lo anterior es que en el ejercicio de sus competencias en materia de consumo, los municipios han de apoyar la participación de las organizaciones y asociaciones de consumidores que están especialmente llamadas a colaborar con la Administración en las actuaciones de interés común especialmente las que se dirijan a la satisfacción directa de los legítimos intereses de los consumidores ${ }^{126}$. Precisamente este último mandato -que es razón máxima de su existencia-, implica la exclusividad para la audiencia, consulta, representación y participación en la defensa de dichos derechos e intereses generales de los consumidores anta la Administración correspondiente -en este caso la municipal- sin perjuicio de las competencias de las restantes administraciones en materia de consumo ${ }^{127}$. El estatus de asociación de consumidores y usuarios implica que, también las de ámbito local, son las únicas legitimadas para actuar en nombre y representación de los intereses generales de los consumidores y usuarios ${ }^{128}$. Su especial situación y la misión que el ordenamiento le atribuye, hace que tengan un régimen jurídico básico específico regulado en el Título II del Texto Refundido de la Ley General para la Defensa de los Consumidores y Usuarios con requisitos especiales en su constitución, régimen de funcionamiento e independencia. Por su parte, la legislación autonómica, a su vez, ha regulado con profusión su estatuto de tal manera que existe una prohibición formal ex lege para aquellas organizaciones que no reúnan los requisitos exigidos en el Texto refundido o en la normativa autonómica aplicable, a la hora de denominar una asociación con los términos «consumidor o usuario», junto a cualquier otra expresión similar que induzca a error o confusión sobre su naturaleza o su legitimidad para la defensa de los derechos e intereses de los consumidores y usuarios, ${ }^{129}$. Esta cuestión ha llevado a que ciertas ordenanzas locales establezcan que las organizaciones de consumidores que no reúnan los requisitos exigidos en la legislación estatal o autonómica de protección de los consumidores, sólo puedan representar los intereses de sus asociados o los de la organización, no los intereses generales, colectivos o difusos del resto de consumidores ${ }^{130}$, y ello sin perjuicio de su representatividad para la defensa de los intereses generales o sectoriales de los vecinos a los efectos del art. 236 del Reglamento de Organización, Funcionamiento y Régimen Jurídico de las Entidades Locales ${ }^{131}$.

122 STS, Contencioso sección 4, del 29 de Septiembre del 2003 (ROJ: STS 5794/2003). Recurso: 5167/1998.

123 En este sentido véase la STS, Contencioso sección 4 del 30 de Noviembre del 2010 (ROJ: STS 6428/2010). Recurso: $1200 / 2008$.

124 STS, Contencioso sección 7 del 14 de Febrero del 2013 (ROJ: STS 693/2013). Recurso: 4118/2011.

125 Art. 97.1 b) de la Ley 13/2003, de 17 de diciembre, de Defensa y Protección de los Consumidores y Usuarios de Andalucía.

126 Art. 21.4 de la Ley Foral 7/2006, de 20 de junio, de Defensa de los Consumidores y Usuarios.

127 Art. 52 de la Ley 2/2012, de 28 de marzo, gallega de protección general de las personas consumidoras y usuarias.

128 Art. 24.1 del Real Decreto Legislativo 1/2007, de 16 de noviembre, por el que se aprueba el texto refundido de la Ley General para la Defensa de los Consumidores y Usuarios y otras leyes complementarias.

129 Art. 25 del del Real Decreto Legislativo 1/2007, de 16 de noviembre, por el que se aprueba el texto refundido de la Ley General para la Defensa de los Consumidores y Usuarios y otras leyes complementarias.

130 Art. 51.2 de la Ordenanza de Consumo de la Ciudad de Madrid (BO. Comunidad de Madrid núm. 89, de 15-04-2011).

131 El art. 236 señala que "los derechos reconocidos a las asociaciones para la defensa de los intereses generales o sectoriales de los vecinos en los artículos 232, 233, 234 y 235 de este Reglamento sólo serán ejercitables por aquellas que se encuentren inscritas en el Registro Municipal de Asociaciones Vecinales". 
No cabe duda, pues, que la organizaciones de consumidores y usuarios y su especial posición jurídica representan una relación especial de sujeción: son una manifestación más de las relaciones especiales jurídico-administrativas ya que, como el mismo GALLEGO ANABITARTE afirma, no existe una relación especial de sujeción como ente abstracto y único o modelo general, sino relaciones especiales de sujeción ${ }^{132}$.

La especial situación de las asociaciones de consumidores y la de los consumidores finales, conforme a la previsión de nuestra Carta Magna, facilitan la promoción e institucionalización de órganos de participación ciudadana, en materia de consumo, en el conjunto de la legislación autonómica sobre consumidores y usuarios. Los Consejos Regionales del Consumo o Comisión Consultiva de Consumo, en el caso del País Vasco, se conciben como órganos consultivos, asesores y de participación en materia de consumo, junto a un papel de coordinación interadministrativa, dadas las competencias municipales en la materia. Son, por excelencia, los órganos colegiados de representación y debate en materia de consumo, en los que desde luego están integrados los representantes de las organizaciones de consumidores y usuarios de cada ámbito regional. Su consulta es preceptiva para la adopción de aquellas disposiciones generales que afecten directamente a la protección y defensa de los consumidores ${ }^{13}$. En la Comunidad Autónoma Andaluza se prevé la existencia, junto al Consejo Andaluz de Consumo, de los Consejos Provinciales de Consumo ${ }^{134}$. Sin embargo, tan sólo la Ley murciana de defensa de consumidores y usuarios contempla la posibilidad de creación de Consejos Municipales de Consumo: «Los municipios impulsarán la creación de consejos de consumo, como órganos colegiados de carácter consultivo en el diseño y aplicación de las políticas públicas que afecten al ámbito de la defensa del consumidor y usuario. Estos consejos estarán integrados por representantes de los sectores implicados y, en todo caso, por las más representativas de su ámbito territorial ${ }^{135}$ \%. Por lo tanto, entra dentro de las facultades de ordenación normativa local la creación de órganos consultivos y de participación municipal de consumo. Opción que se ha materializado, por ejemplo en el caso del Ayuntamiento de Madrid ${ }^{136}$, Castellón ${ }^{137}$, Palma de Mallorca ${ }^{138}$ o Valencia ${ }^{139}$.

\subsection{La recepción de las reclamaciones de los consumidores de su ámbito territorial y la realización de mediación entre los consumidores y las empresas}

Esta es una atribución competencial unánime que la totalidad de las Leyes autonómicas han materializado, salvo la Comunidad de Illes Balears en donde se remite a los términos establecidos por la legislación de régimen local y siempre bajo la vía de la delegación competencial ${ }^{40}$. Sin perjuicio del encuadramiento que realizan diversas leyes autonómicas de esta competencia local dentro de las Oficinas municipales de Información al consumidor, estas actuaciones son claves en la protección eficiente y real de los consumidores y usuarios. De hecho, la mejora en el acceso a vías de reclamaciones sencillas, eficientes, expeditivas y de bajo coste -lo que incluye el acceso a mecanismos de resolución alternativa de litigios por parte de los consumidores- es un objetivo de acción en las políticas de la Unión Europea ${ }^{141}$. En el terreno conceptual, el Código de Consumo de Cataluña ofrece una definición de las actividades de mediación: «La mediación de consumo es un procedimiento que se caracteriza por la intervención de una tercera persona imparcial y experta, que tiene como objeto ayudar a las partes y facilitar la obtención por ellas mismas de un acuerdo satisfactorio $\left.{ }^{142}\right)$. Procedimiento que la Ley gallega caracteriza como voluntario, imparcial, confidencial y universal ${ }^{143}$, el cual según la ley valenciana de consumidores debe atenerse además a la transparencia, eficacia y equidad ${ }^{144}$.

132 Gallego AnABitARTE, Alfredo "Las relaciones especiales de sujeción y el principio de legalidad de la Administración”, RAP núm. 34, enero-abril de 1961, pág. 24.

133 Art. 28 de la Ley 11/1998, de 9 de julio, de Protección de los Consumidores de la Comunidad de Madrid, el art. 18.2 de la Ley 6/2001, de 24 de mayo, del Estatuto de los Consumidores de Extremadura, el art. 39.3 de la Ley 13/2003, de 17 de diciembre, de Defensa y Protección de los Consumidores y Usuarios de Andalucía, art. 28 de la Ley 1/2011, de 22 de marzo, de la Generalitat, por la que se aprueba el Estatuto de los Consumidores y Usuarios de la Comunitat Valenciana, entre otras.

134 Art. 38.1 de la Ley 13/2003, de 17 de diciembre, de Defensa y Protección de los Consumidores y Usuarios de Andalucía.

135 Art. 18 de la Ley 4/1996, de 14 de junio, del Estatuto de consumidores y usuarios de la Región de Murcia.

136 Art. 53 de la Ordenanza de Consumo de la Ciudad de Madrid (BO. Comunidad de Madrid núm. 89, de 15-04-2011).

137 Art. 8 de la Ordenanza reguladora de los servicios locales de consumo, 15 de marzo de 1991 (BOP núm. 46, correspondiente al día 13 de abril de 1991).

138 Art. 18 de la Ordenanza de Consumo del Ayuntamiento de Palma, de 27-09-2012 (BOIB núm. 182, de 06-12-2012).

139 Art. 13 de la Ordenanza municipal reguladora de los servicios de consumo del Ayuntamiento de Valencia (BOP núm. 154, de 1-VII-93) que denomina como Consejo Sectorial de Consumo.

140 Art. 93 de la Ley 7/2014, de 23 de julio, de protección de las personas consumidoras y usuarias de las Illes Balears.

141 Art. 3 C) del Reglamento (UE) 254/2014 del Parlamento Europeo y del Consejo de 26 de febrero de 2014 sobre el Programa plurianual de Consumidores para el período 2014-2020 (DOUE de 20-3-2014).

142 Art. 132-1 de la Ley 22/2010, de 20 de julio, del Código de consumo de Cataluña.

143 Art. 44.1 de la Ley $2 / 2012$, de 28 de marzo, gallega de protección general de las personas consumidoras y usuarias.

144 Art. 78.2 de la Ley 1/2011, de 22 de marzo, de la Generalitat, por la que se aprueba el Estatuto de los Consumidores y Usuarios de la Comunitat Valenciana. 
Para esta misión mediadora son fundamentales las administraciones locales por su cercanía al ciudadano y su contrastada experiencia en esta materia. Conscientes de esta realidad algunas leyes han establecido un sistema unificado de reclamaciones para todos los municipios de su ámbito territorial para garantizar el tratamiento homogéneo de las reclamaciones ${ }^{145}$ remitiendo algunas de ellas a una regulación reglamentaria el «procedimiento administrativo» (sic) de tramitación de las denuncias y reclamaciones de las personas consumidoras y usuarias presentadas ante las Administraciones públicas con competencias en materia de consumo contra empresas y profesionales, sin perjuicio de las actuaciones de inspección y sanción a que pudieran dar lugar ${ }^{146}$. Procedimiento que ha sido objeto de regulación sucinta en el caso del Ayuntamiento de Madrid ${ }^{147}$. ¿Podemos hablar realmente de un procedimiento administrativo en el ejercicio de la mediación por parte de la administración en la tramitación de denuncias entre particulares y empresarios como lo hace la Ley de consumidores del País Vasco?

Cuestión fundamental al respecto es lo establecido por el art. 3.1 del Real Decreto 231/2008, de 15 de febrero, por el que se regula el Sistema Arbitral de Consumo de Cataluña, al calificar la actividad de las Juntas Arbitrales de Consumo como de carácter administrativo. Naturaleza que viene confirmada en algunos preceptos del texto mencionado. Así, por ejemplo, en la resoluciones sobre la causas de inadmisión de solicitudes de arbitraje de consumo y en el recurso contra la admisión o inadmisión de la solicitud de arbitraje ${ }^{148}$. Sin embargo, el Decreto 98/2014, de 8 de julio, sobre el procedimiento de mediación en las relaciones de consumo de Cataluña, no hace mención alguna a la naturaleza del procedimiento, a pesar de su regulación específica, si bien determinados elementos nos hacen ver que nos encontramos ante un procedimiento de naturaleza administrativa: la determinación de naturaleza ejecutiva de los acuerdos de mediación ${ }^{149}$ o lo relativo a la admisión de la solicitud de mediación ${ }^{150}$. Apunta en dirección a su naturaleza administrativa la ejecutividad apuntada en algunas leyes respecto del resultado de dicha mediación ${ }^{151}$. TRAYTER señala que «la mediación se distingue del arbitraje en que el mediador no resuelve por sí mismo, mientras que el árbitro adopta una decisión (laudo) a la que las partes han de someterse. El mediador, por el contrario, no puede imponer su decisión sino que corresponde a las partes lograr un acuerdo ${ }^{152}$ ». Sin duda que podríamos hablar de procedimiento administrativo triangular ${ }^{153}$, cuyo resultado final puede concluir bien con la avenencia de las partes enfrentadas, bien con la posibilidad de realizar un arbitraje institucional o la de acudir directamente a la vía jurisdiccional.

\subsection{El fomento y la divulgación del Sistema Arbitral de Consumo}

Más arriba decíamos que la actividad de las Juntas Arbitrales de Consumo es de carácter administrativo. Es más, son órganos administrativos de gestión del arbitraje institucional y sus resoluciones ponen fin a la vía administrativa ${ }^{154}$.

Si bien la gran mayoría de las leyes autonómicas atribuyen esta competencia de forma explícita a los municipios, en otras, aparece bajo el ropaje de las «distintas administraciones públicas» de la comunidad respectiva, como responsables del fomento y divulgación del sistema arbitral de consumo. Por tanto, podemos hablar en este caso, de una atribución indirecta en el caso de las Comunidades de Castilla y León, Cataluña (art. 131-1 del estatuto de consumidor), Aragón e Illes Balears. Por su parte, la Comunidad Valenciana atribuye a los municipios, la función de colaborar y participar en el sistema arbitral de consumo ${ }^{155}$. En cambio, las leyes de consumidores y

145 Art. 32 de Ley 11/1998, de 9 de julio, de Protección de los Consumidores de la Comunidad de Madrid.

146 Art. 12 de la Ley 6/2003, de 22 de diciembre, de Estatuto de las Personas Consumidoras y Usuarias del País Vasco. En Cataluña existe esta norma Decreto 98/2014, de 8 de julio, sobre el procedimiento de mediación en las relaciones de consumo. (DOGC de 10-07-2014). La Ley 16/2006, de 28 de diciembre, de Protección y Defensa de los Consumidores y Usuarios de Aragón, en su art. 20.2, califica el procedimiento de mediación, igualmente a como lo hace la ley del País Vasco, como un procedimiento administrativo.

147 Art. 37 de la Ordenanza de Consumo de la Ciudad de Madrid (BO. Comunidad de Madrid núm. 89, de 15-04-2011).

148 Arts. 35 y 36 del Real Decreto 231/2008, de 15 de febrero, por el que se regula el Sistema Arbitral de Consumo.

149 Sin embargo, "Cuando la Administración actúa como mediadora en un conflicto de consumo no ejercita competencias de inspección y control dirigidas a verificar la adecuación de conductas a la legalidad y, por tanto, la falta de colaboración por parte del empresario a los requerimientos que se le formulen no es constitutivo de infracción administrativa" Cordero Lobato, Encarna (2013) "¿Debe el empresario colaborar con la administración de consumo en procedimientos de mediación y arbitraje?” Revista CESCO de Derecho de Consumo núm. 6/2013, pág. 57.

150 Arts. 30, 16 y 17 del Decreto 231/2008, de 15 de febrero, por el que se regula el Sistema Arbitral de Consumo de Cataluña.

151 Art. 44.3 de la Ley 2/2012, de 28 de marzo, gallega de protección general de las personas consumidoras y usuarias. En este sentido también el art. 132-3 de la Ley 22/2010, de 20 de julio, del Código de consumo de Cataluña y los arts. 28 y ss del Decreto 1/2010, de 14 de enero, del Consejo de Gobierno, por el que se aprueba el Reglamento de la Ley 11/1998, de 9 de julio, de Protección de los Consumidores de la Comunidad de Madrid.

152 TrAYtER, José Manuel (1997), “El arbitraje de derecho administrativo”. Revista de Administración Pública núm. 143, mayo-agosto 1997, pág. 82.

153 GAmero CASAdo, Eduardo y FernÁndez Ramos, Severiano (2010), Manual Básico de Derecho Administrativo. Ed. Tecnos, Madrid 7. edición, pág. 310.

154 Arts. 5.1 y 35 del Real Decreto 231/2008, de 15 de febrero, por el que se regula el Sistema Arbitral de Consumo.

155 Art. 13.1e) de la Ley 1/2011, de 22 de marzo, de la Generalitat, por la que se aprueba el Estatuto de los Consumidores y Usuarios de la Comunitat Valenciana.

REALA, Nueva Época, - N. ${ }^{\circ}$, enero-junio 2016 - ISSN: 1989-8975 - DOI: 10.24965/reala.voi5.10355 
usuarios de las Comunidades de Castilla la Mancha, Murcia, Canarias no atribuyen competencias en esta materia a los municipios. El Principado de Asturias tampoco realiza una atribución competencial directa a los municipios, aunque sí establece el fomento de su implantación en las administraciones locales con el fin de posibilitar el acceso de todos los ciudadanos al arbitraje en materia de consumo, estableciendo, al mismo tiempo, que las oficinas de titularidad pública podrían ser sede de la correspondiente Junta Arbitral de Consumo ${ }^{156}$, lo cual viene a reconocer ciertas competencias municipales en la materia y lo que es más importante, la vinculación directa entre las Oficinas municipales de información al consumidor, la mediación y la actividad arbitral.

Desde luego que estas competencias locales están más que justificadas desde la acción normativa de la U.E. que reclama «una intervención legislativa inteligente» y contempla una acción directa para facilitar y mejorar del acceso a sistemas de resolución de litigios sencillos, eficientes y de bajo coste para los consumidores, y especialmente implantar sistemas alternativos de resolución de litigios ${ }^{157}$.

De ahí que podamos decir que la actividad legislativa autonómica establezca una doble línea de fomento: una primera, con un mandato específico a las Administraciones autonómicas para que contribuyan al establecimiento de estructuras y órganos arbitrales en los municipios y otra segunda, de fomento directo a los municipios con la asignación específica de competencias de fomento, según los casos expresados. Fomento que en la Comunidad de Madrid se liga también a la colaboración con la Administración del Estado ya que también forma parte del Sistema Arbitral de Consumo ${ }^{158}$. Para este fin, alguna ley autonómica ha elegido el instrumento administrativo para ejecutar dicho mandato y es el convenio interadministrativo tanto con municipios, como con mancomunidades, como es el caso de la Comunidad Autónoma del País Vasco ${ }^{159}$.

La legislación autonómica, en general y en la línea apuntada de fomento, obliga a que las sociedades mercantiles públicas autonómicas que mantengan relaciones de consumo, a su adhesión al arbitraje de consumo ${ }^{160}$. Mandato que en otras leyes autonómicas se extiende a las entidades o empresas privadas que gestionen servicios públicos, (incluyendo la ley andaluza también las de «interés general» ${ }^{161}$ ). De igual forma, se prevé la incentivación a las empresas que perciban ayudas o subvenciones públicas para la adhesión a dicho sistema ${ }^{162}$, incluso algunas leyes han establecido la introducción de la adhesión al sistema arbitral de consumo como criterio objetivo a tener en cuenta para la adjudicación de contratos por la Administración pública correspondiente y su sector público, cuando el objeto del contrato suponga que la empresa adjudicataria mantenga relaciones de consumo con consumidores ${ }^{163}$. Incluso la ley aragonesa de consumidores y la de Illes Balears señalan que sus respectivas administraciones considerarán la adhesión al sistema arbitral de consumo como mérito objetivo en la valoración de premios a la calidad empresarial que tengan establecidos o pudieran establecer ${ }^{164}$.

Es verdad que de forma indirecta las Comunidades Autónomas en su producción legislativa sobre el presente régimen jurídico, han propiciado la creación de formas de arbitraje extrajudicial para el conjunto de sus administraciones públicas de su ámbito territorial, pero, otras, de manera explícita, como la Ley de consumidores de la Comunidad de Madrid, incluyen a las corporaciones locales, en dichas acciones para la adopción del sistema arbitral de consumo en la resolución de conflictos y las reclamaciones de los consumidores surgidos en su actividad, tanto en las empresas públicas o como en las privadas que gestionen servicios públicos o reciban recursos de aquéllas, y que este hecho sea expresado y plasmado en los documentos contractuales respectivos ${ }^{165}$. Mandato explícito que obliga a las Administraciones locales de estas Comunidades a una acción positiva de promoción dentro de su ámbito de organización y funcionamiento, y dentro de su sector público.

En definitiva, las leyes autonómicas sobre consumidores y usuarios en su inmensa mayoría otorgan capacidades a las Corporaciones locales en la promoción del sistema arbitral, lo cual implica que su acción no sólo se desarrolle en el terreno de la acción de fomento sino también en la creación, diseño y gestión de un sistema arbitral de

156 Arts 21.2 y 28.1 de la Ley del Principado de Asturias 11/2002, de 2 de diciembre, de los Consumidores y Usuarios.

157 Art. 3.1. c) del Reglamento (UE) N o 254/2014 del Parlamento Europeo y del Consejo de 26 de febrero de 2014 sobre el Programa plurianual de Consumidores para el período 2014-2020.

158 Art. 63.1 f) de la Ley 11/1998, de 9 de julio, de Protección de los Consumidores de la Comunidad de Madrid.

159 Art. 13.3 en relación con el art. 70 de la Ley 6/2003, de 22 de diciembre, de Estatuto de las Personas Consumidoras y Usuarias de Euskadi.

160 Es el caso por ejemplo del art. 113.2 de la Ley 6/2003, de 22 de diciembre, de Estatuto de las Personas Consumidoras y Usuarias de Euskadi, el art.37 de la Ley Foral 7/2006, de 20 de junio, de defensa de los consumidores y usuarios de Navarra, el art. 43.4 de la Ley 2/2012, de 28 de marzo, gallega de protección general de las personas consumidoras y usuarias. por poner un ejemplo.

161 Art. 15.3 de la Ley 13/2003, de 17 de diciembre, de Defensa y Protección de los Consumidores y Usuarios de Andalucía.

162 Art. 28.3 de la Ley del Principado de Asturias 11/2002, de 2 de diciembre, de los Consumidores y Usuarios.

163 Art. 43.6 de la Ley 2/2012, de 28 de marzo, gallega de protección general de las personas consumidoras y usuarias.

164 Art. 23.4 de la Ley 16/2006, de 28 de diciembre, de Protección y Defensa de los Consumidores y Usuarios de Aragón, y el art. 53.3 de la Ley 7/2014, de 23 de julio, de protección de las personas consumidoras y usuarias de las Illes Balears.

165 Art. 31.3 de la Ley 11/1998, de 9 de julio, de Protección de los Consumidores de la Comunidad de Madrid.

REALA, Nueva Época, - N. ${ }^{\circ}$ 5, enero-junio 2016 - ISSN: 1989-8975 - DOI: 10.24965/reala.voi5.10355 
consumo, con sus funciones y tipología de órganos, para la solución de los conflictos que se señala en los artículos 6 y 18 del Real Decreto 231/2008, de 15 de febrero, por el que se regula el Sistema Arbitral de Consumo.

\subsection{El ejercicio de las acciones judiciales que en defensa de los consumidores y usuarios}

No es ni mucho menos, en la legislación autonómica, una atribución competencial generalizada para los municipios ya que tan sólo se explicita en las leyes de consumidores y usuarios de Murcia, Andalucía y Galicia ${ }^{166}$ aunque tal competencia fluye, como ya señalamos más arriba, desde el propio Texto refundido de la Ley General para la Defensa de los Consumidores y Usuarios ${ }^{167}$, cuando se concede a las Corporaciones locales la legitimación para el ejercicio de la acción de cesación frente a las conductas contrarias a lo dispuesto en la ley de consumidores en materia de cláusulas abusivas, contratos celebrados fuera de establecimiento mercantil, venta a distancia, garantías en la venta de productos, viajes combinados y cualquier otra conducta contraria que lesione intereses colectivos o intereses difusos de los consumidores y usuarios.

La Ley de la Región de Murcia es la más explícita e incluye la legitimación para las acciones de cesación, retractación y declarativas de condiciones generales de la contratación ${ }^{168}$. En la misma línea, la Ley andaluza atribuye a las Administraciones locales el ejercicio de acciones civiles en defensa de los consumidores vecinos de su localidad de conformidad con lo que establezca la legislación estatal que reconozca a las Administraciones Públicas en general esta legitimación ${ }^{169}$.

La acción de cesación se dirige a obtener una sentencia que condene al demandado a cesar en el comportamiento lesivo y el de la prohibición judicial de reiteración futura de ese comportamiento. Asimismo, la acción puede ejercerse para prohibir la realización de una conducta cuando esta haya finalizado al tiempo de ejercitar la acción, si existen indicios suficientes que hagan temer su reiteración de modo inmediato ${ }^{170}$. El Texto Refundido considera también ejercitable la acción de cesación cuando el empresario recomiende o posibilite la utilización de cláusulas abusivas ${ }^{171}$.

La cuestión fundamental de cara al ejercicio competencial de las corporaciones locales es la legitimación que, en el caso de que los intereses estén determinados o sean fácilmente determinables, su competencia es plena, de tal manera que naturalmente pueden promover o personarse en los procedimientos judiciales mencionados. Ahora bien, la legitimación de la corporación local respectiva, tiene límites ya que cuando los perjudicados por un hecho dañoso sean una pluralidad de consumidores o usuarios indeterminada o de difícil determinación, la legitimación para demandar en juicio la defensa de estos intereses difusos ${ }^{172}$ corresponderá exclusivamente a las asociaciones de consumidores y usuarios que, conforme a la Ley, sean representativas ${ }^{173}$. Referencias legislativas que suponen recoger una nueva tendencia para nuestro ordenamiento que «al igual que el europeo resulta algo ajeno a las llamadas "class action", o acciones colectivas, tan desarrolladas en el sistema legal norteamericano ${ }^{174 » .}$ A este respecto debe tenerse en cuenta que se opone a lo difuso la «determinabilidad» tanto por la materia como respecto del grupo de consumidores o usuarios interesados ${ }^{175}$. A este respecto, debemos recordar que el concepto de legitimación encierra un doble significado: la llamada legitimación «ad processum» y la legitimación «ad causam». La primera viene a referirse a la facultad de promover la actividad del órgano decisorio, es decir, la aptitud genérica de ser parte en cualquier proceso, lo que es lo mismo que capacidad jurídica o personalidad, porque toda perso-

166 Art. 55 de la Ley 2/2012, de 28 de marzo, gallega de protección general de las personas consumidoras y usuarias.

167 Art. 54.3 a) del Real Decreto Legislativo 1/2007, de 16 de noviembre, por el que se aprueba el texto refundido de la Ley General para la Defensa de los Consumidores y Usuarios y otras leyes complementarias.

168 Art. 45.2 e) de la Ley 4/1996, de 14 de junio, del Estatuto de consumidores y usuarios de la Región de Murcia.

169 Art. 97.1 d) de la Ley 13/2003, de 17 de diciembre, de Defensa y Protección de los Consumidores y Usuarios de Andalucía.

170 Art. 53 del Real Decreto Legislativo 1/2007, de 16 de noviembre, por el que se aprueba el texto refundido de la Ley General para la Defensa de los Consumidores y Usuarios y otras leyes complementarias.

171 Este apartado trae causa del art. 7 de la Directiva 93/13/CEE del Consejo, de 5 de abril de 1993, sobre las cláusulas abusivas en los contratos celebrados con consumidores, Diario Oficial $n^{\circ} \mathrm{L} 095$ de 21-04-1993.

172 Para la tutela de estos intereses difusos es necesario que la asociación tenga que estar representada en el Consejo de Consumidores y Usuarios: "el ejercicio de la acción de cesación contra la utilización de condiciones generales de la contratación abusivas en los contratos celebrados con consumidores, no queda abierta a cualquier asociación que esté legalmente constituida, aunque en sus estatutos conste como finalidad la tutela de los intereses de consumidores y usuarios. Es preciso que la asociación, cuando es de ámbito supra autonómico -en el caso de autos no se cuestiona que la demandante tiene tal carácter-, esté inscrita en el Registro Estatal de Asociaciones de Consumidores y Usuarios" STS, civil sección 1, de 13 de octubre de 2014 (ROJ: STS 4427/2014). Núm. de Recurso: 1161/2012. La STS, civil sección 1, de 29 de diciembre de 2010 (ROJ: STS 7551/2010). Núm. de Recurso: 1074/2007, habla de asociaciones “representativas". En este mismo sentido la STC 96/2012, de 7 de mayo de 2012.

173 Art. 11.3 de la Ley 1/2000, de 7 de enero, de Enjuiciamiento Civil, de aplicación directa por remisión del art. 54.3 del Real Decreto Legislativo 1/2007, de 16 de noviembre, por el que se aprueba el texto refundido de la Ley General para la Defensa de los Consumidores y Usuarios.

174 STS, contencioso sección 4, de 19 de junio de 2012 (ROJ: STS 4278/2012). Núm. de Recurso: 3934/2010.

175 STS, civil sección 1, de 29 de diciembre de 2010 (ROJ: STS 7551/2010). Núm. de Recurso: 1074/2007. Núm. de Resolución: 861/2010.

REALA, Nueva Época, - N. ${ }^{\circ}$, enero-junio 2016 - ISSN: 1989-8975 - DOI: 10.24965/reala.voi5.10355 
na, por el hecho de serlo, es titular de derechos y obligaciones y puede verse en necesidad de defenderlos ${ }^{176}$, y la segunda tiene que ver con la aptitud para ser parte en un proceso determinado, lo que significa que depende de la pretensión procesal que ejercite el actor o en lo que podríamos determinar como la legitimación propiamente dicha ${ }^{177}$, e implica una relación especial entre una persona y una situación jurídica en litigio, por virtud de la cual es esa persona la que debe actuar como actor o demandado en ese pleito. De ahí que la legitimación activa ad causam presente también una dimensión sustantiva y, por tanto, -como reiteradamente ha afirmado la jurisprudencia de la sala de lo civil y de lo contencioso administrativo del Tribunal Supremo- tenga que ver con el fondo de asunto ${ }^{178}$.

\subsection{Adoptar las medidas urgentes y requerir las colaboraciones precisas en los supuestos de crisis o emergen- cias que afecten a la salud o seguridad de los consumidores o usuarios.}

Esta competencia está en directa conexión con la salubridad pública, extremo competencial explícitamente contemplado como «propio» de los municipios en el art. 25.2 de la LRBRL, y que se incluye también en la Ley General de Sanidad cuando atribuye a los municipios el control sanitario de la distribución y suministro de alimentos, bebidas y demás productos que estén directa o indirectamente relacionados con el uso o consumo humanos, así como los medios de su transporte ${ }^{179}$. De ahí que las autoridades locales estén también facultadas para adoptar las medidas preventivas que estimen pertinentes, tales como la incautación o inmovilización de productos, suspensión del ejercicio de actividades, cierres de Empresas o de sus instalaciones, intervención de medios materiales y personales y cuantas otras consideren sanitariamente justificadas, cuando exista o se sospeche razonablemente la existencia de un riesgo inminente y extraordinario para la salud ${ }^{180}$. En consonancia con esta función, la Ley General de Sanidad apoya la decisión de dichas autoridades en la labor del personal al servicio de las Administraciones Públicas que desarrolle las funciones de inspección, cuando ejerzan las mismas y con las facultades que dicha ley les otorga, entre otras, entrar libremente y sin previa notificación, en cualquier momento, en todo Centro o establecimiento sujeto a Ley General de Sanidad ${ }^{181}$. Por tanto, podemos decir que esta competencia específica es una competencia local «propia» engarzada más directamente sobre las de «protección de la salubridad pública» aunque con una conexión evidente con la defensa de consumidores y usuarios.

Las leyes autonómicas de consumidores y usuarios autonómicas en su mayoría han contemplado estas facultades a la hora de proceder a esta atribución competencial a los municipios en sus respectivas leyes ${ }^{182}$, añadiendo a la protección de la a la salud y lo seguridad, la de los intereses económicos de las personas consumidoras y usuarias. Todas instan a la corporación local a la «adopción» de la medidas, por lo que existe una capacidad indudable para la iniciativa local en esta materia, si bien, algunas las leyes de consumidores y usuarios establecen que, en función de la trascendencia, de la extensión y de la gravedad de las conductas lesivas, número de personas consumidoras y usuarias afectadas, y la urgencia, dicha competencia puede verse asumida por los órganos competentes en materia de consumo del Gobierno autonómico correspondiente. Este es el caso de las Comunidades del País Vasco y Madrid ${ }^{183}$. No se pronuncian sobre esta cuestión competencial ley de Cantabria, Murcia, Illes Balears ${ }^{184}$,

176 STS, contencioso sección 3, de 7 de abril de 2005 (ROJ: STS 2090/2005). Núm. de Recurso: 5572/2002.

177 STS, contencioso sección 3, del 2 de diciembre de 2013 (ROJ: STS 5800/2013). Núm. de Recurso: 4479/2010. De forma repetida la jurisprudencia de la sala de lo civil de Tribunal supremo señala que "la legitimatio ad causam activa se visualiza en una perspectiva de relación objetiva, entre el sujeto que demanda y el objeto del proceso; más concretamente, entre el derecho o situación jurídica en que se fundamenta la pretensión y el efecto jurídico pretendido". STS, civil sección 1, de 4 de diciembre de 2015 (ROJ: STS 5147/2015). Núm. de Recurso: $2337 / 2013$.

178 Entre otras la STS, civil, de 21 de noviembre de 2013, rec. núm. 1951/2011, la STS, civil, de 12 de marzo de 2012, rec. núm. 1203/2008, y la STS, civil, de 15 de octubre de 2013, rec. núm. 1268/2011. La STS, contencioso sección 3, de 7 de junio de 2006 (RC 7978/2003), la STS, contencioso sección 3, de 22 de noviembre de 2001, rec. núm. de Recurso: 2134/1999, la STS, contencioso sección 6, de 18 de junio de 1997, rec. núm.: $7696 / 1992 \ldots$

179 Art. 42.3 de la Ley 14/1986, de 25 de abril, General de Sanidad.

180 Art. 26.1 de la Ley 14/1986, de 25 de abril, General de Sanidad.

181 El art. 16 del Real Decreto Legislativo 1/2007, de 16 de noviembre, por el que se aprueba el texto refundido de la Ley General para la Defensa de los Consumidores y Usuarios y otras leyes complementarias, establece como medidas extraordinarias ante situaciones de urgencia y necesidad, y de extrema gravedad que determinen una agresión indiscriminada a la salud y seguridad de los consumidores y usuarios en más de una comunidad autónoma, la creación de un órgano en el que se integren y participen activamente las comunidades autónomas afectadas, que asumirá, las facultades administrativas que se le encomienden para garantizar la salud y seguridad de las personas, sus intereses económicos y sociales, la reparación de los daños sufridos, la exigencia de responsabilidades y la publicación de los resultados.

182 Así, por ejemplo, el art. 52 e) de la Ley del Principado de Asturias 11/2002, de 2 de diciembre, de los Consumidores y Usuarios, el art. 6.2 e) de la Ley 11/2005, de 15-12-2005, del Estatuto del Consumidor, el art. 13.2 b) de la Ley 1/2011, de 22 de marzo, de la Generalitat, por la que se aprueba el Estatuto de los Consumidores y Usuarios de la Comunitat Valenciana, el art. 46.1 c) de la Ley 3/2003, de 12 de febrero, del Estatuto de los Consumidores y Usuarios de la Comunidad Autónoma de Canarias, el art. 5 g) de la Ley 5/2013, de 12 de abril, para la defensa de los consumidores en la Comunidad Autónoma de La Rioja.

183 Art. 68.1b) de la Ley 6/2003, de 22 de diciembre, de Estatuto de las Personas Consumidoras y Usuarias del País Vasco y el art. 63.2 C) de la Ley 11/1998, de 9 de julio, de Protección de los Consumidores de la Comunidad de Madrid.

184 Si bien el art. 52 p) de la Ordenanza de Consumo del Ayuntamiento de Palma de Mallorca, de 27 de septiembre de 2012 (BOIB núm. 182, de 06-12-2012), sí que prevé dicha competencia como propia.

REALA, Nueva Época, - N. ${ }^{\circ}$ 5, enero-junio 2016 - ISSN: 1989-8975 - DOI: 10.24965/reala.voi5.10355 
Andalucía, Navarra y el Estatuto del Consumidor de Castilla y León ${ }^{185}$. Por su parte, la ley gallega establece que la adopción de medidas urgentes, deben ser comunicadas de forma inmediata al órgano autonómico competente en materia de consumo ${ }^{186}$ y el Estatuto de los Consumidores de Extremadura, señala, con bastante poca precisión, que los municipios deben mejorar los sistemas de intercambio de información en los casos de alertas, accidentes, productos peligrosos, etc. ${ }^{187}$.

Finalmente, hemos de recordar que uno de los primeros pronunciamientos del Tribunal Constitucional sobre seguridad y orden público, fue a consecuencia de cuestiones referentes a la salubridad pública y, en concreto, en un caso de seguridad alimentaria de los consumidores, en la que se alertaba sobre la posibilidad de la existencia de mejillones en mal estado en la provincia de Barcelona comunicando de este peligro a los distintos Ayuntamientos con preferencia a la Comunidad Autónoma ${ }^{188}$, definiéndose claramente por el Alto Tribunal como una cuestión de seguridad pública.

\section{CONCLUSIONES}

La desaparición de las competencias en materia de la defensa de los consumidores y usuarios para los municipios del art. 25.2 de la LRBRL según la modificación operada por la LSRL, en realidad no ha supuesto un cambio real de la situación, ya que estas atribuciones han gozado de raigambre y tradición en el entorno local por su necesaria cercanía con los consumidores y usuarios. Es más, el conjunto normativo sectorial tanto de la Administración General del Estado como de las CC.AA han contemplado a los municipios como administraciones con atribuciones claras en dicha materia. Pero sobre todo, las CC.AA se han convertido en una fuente alternativa competencial en materia de la defensa de consumidores y usuarios frente al Estado, tras la modificación operada por la LRSAL de las competencias municipales calificadas como propias, de tal manera que la fuente real de estas competencias en la materia, se residencia de manera prioritaria en los propios Estatutos de Autonomía y en la legislación sectorial autonómica, en detrimento de la legislación estatal de régimen local. Los municipios, como hemos señalado, son una pieza básica y relevante en este sector de la acción administrativa que necesita irremediablemente de la proximidad, eficacia y eficiencia de la que habla la LRBRL para la defensa de los consumidores y usuarios. Precisamente, sea de una u otra manera, como competencia propia o delegada, el ejercicio competencial pasa por el respeto absoluto de la autonomía local, por muchas que sean las facultades de control de la Administración delegante en este último caso, de tal manera que no se puede situar al municipio en una posición de subordinación cuasijerárquica, sin capacidad alguna para determinar la organización de dichos servicios a la hora de ejecutar potestades delegadas, dado que nos hallamos ante una atribución directamente insertada en el régimen de autonomía establecida en el art. 140 CE. La realidad es que los municipios han sido los primeros garantes en los derechos de los consumidores y usuarios y realizan una labor de protección de los mismos con alcance y resultados contrastados. De ahí que haya sido reconocido por el conjunto legislativo autonómico a través de un número importante de atribuciones que, sin duda, mantiene su posición de primera administración, de cara al ciudadano, en la protección de los consumidores y usuarios.

\section{BIBLIOGRAFÍA}

1. BerMeJo VerA, José (1998), “La Administración inspectora”. RAP núm. 147, septiembre-diciembre 1998.

2. CORDERO LOBATO, Encarna (2013), “¿Debe el empresario colaborar con la administración de consumo en procedimientos de mediación y arbitraje?” Revista CESCO de Derecho de Consumo núm. 6/2013.

3. Gallego Anabitarte, Alfredo, Las relaciones especiales de sujeción y el principio de legalidad de la Administración. RAP núm. 34, enero-abril de 1961.

4. Gamero CaSAdo, Eduardo y Fernández Ramos, Severiano (2010), Manual Básico de Derecho Administrativo. Ed. Tecnos. Madrid 7. ${ }^{\text {a edición. }}$

5. GonzÁlez VAQuÉ, Luis, “La noción de consumidor medio según la jurisprudencia del Tribunal de Justicia de las Comunidades Europeas”, Revista de Derecho Comunitario Europeo, año 8, núm. 17, enero-abril 2004.

6. GUILLÉn CARAMÉS, Javier (2002), El Estatuto jurídico del consumidor (política comunitaria, bases

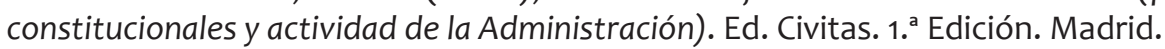

185 Tampoco lo hace la Ley de Consumidores de Aragón pero el art. 59 de la Ley 16/2006, de 28 de diciembre, de Protección y Defensa de los Consumidores y Usuarios de Aragón señala que los Municipios y demás entidades locales ejercerán, en materia de protección del consumidor, las competencias que les atribuye la legislación de régimen local y las señaladas en esta Ley y sus desarrollos reglamentarios.

186 Art. 75.2 d) de la Ley 2/2012, de 28 de marzo, gallega de protección general de las personas consumidoras y usuarias.

187 art. 12.d) de la Ley 6/2001, de 24 de mayo, del Estatuto de los Consumidores de Extremadura.

188 La STC 33/1982, de 8 de junio, avala la decisión de la Administración General del Estado al señalar que la intervención en la materia lo es "por finalidades de seguridad pública, cuya competencia corresponde al Estado en virtud del art. 149.1.29 de la Constitución, siempre que esa intervención esté justificada por razones de necesidad y urgencia”. "El concepto 'seguridad pública', que supone una noción más precisa que la de "orden público". 
7. Morillo-Velarde Pérez, José Ignacio (2014), “Las competencias municipales en Andalucía (las medidas contenidas en el Decreto Ley 7/2014, de 20 de mayo)”. Revista Andaluza de Administración Pública núm. 89.

8. ORTIZ DE LA QUINTANA IBÁÑEZ (2014), “Las Competencias Municipales tras la modificación del régimen local operada con la aprobación de la Ley 27/2013. Especial referencia a la Comunidad Autónoma del País Vasco y Comunidad Foral de Navarra". Academia Vasca de Derecho, Boletín JADO. Bilbao, año XIII, núm. 26, enerodiciembre 2014.

9. Rebollo PUIG, Manuel (2013), "La actividad inspectora” Ponencia para el VIII Congreso de la Asociación Española de Profesores de Derecho Administrativo. Alicante, febrero de 2013.

10. TrAYTER, José Manuel (1997), “El arbitraje de derecho administrativo”. Revista de Administración Pública núm. 143, mayo-agosto 1997. 